\title{
The Political Economy of Psychiatry - Power, Knowledge, and Subjectification in the State/Psychiatry Apparatus
}

by

Darrin Antler

A thesis submitted to the Faculty of Graduate and Postdoctoral Affairs in partial fulfillment of the requirements for the degree of

Master of Arts

in

Political Economy

Carleton University

Ottawa, Ontario

(C) 2020 Darrin Antler 


\begin{abstract}
Mental Health is an issue of great importance to states and governments worldwide. Mental illness is the number one cause of disabilities in Canada and globally. Psychiatry dominates mental health knowledge, discourses and policy, prioritizing a biomedical approach, producing questionable results. The concept of psychiatric disorders is criticized for lacking scientific reliability and validity, psychopharmaceuticals for inefficacy and danger, and coercive practices for violating human rights. Why then does psychiatry continue to dominate mental health policy, practices, discourses and understandings? Applying critical theory of political economy with influences from Marx, Foucault, and others, this thesis argues psychiatry's power and privilege persists through the existence of the state/psychiatry apparatus, consolidating knowledge and power in a process of psychiatric subjectification, creating psychiatric subjects - mentally ill persons. The theory is applied to Canada and Ontario, mapping and explaining the parameters and layers of the apparatus and the political economy of psychiatry.
\end{abstract}




\section{Acknowledgements}

There are many people to whom I am overwhelmingly grateful for their support, council, and advice, without which this project would not have been possible. I must first thank my thesis supervisor, Dr. Marc Andre Gagnon for going above and beyond his duties in assisting me in developing and completing this thesis. His patience and understanding are beyond what was required, and his criticism was always constructive and led to a better version of this work with every piece of advice and guidance. I must also give my thanks to Dr. Cristina Rojas and Donna Coghill, who dedicate themselves to the students who made the choice to study at the Institute of Political Economy at Carleton University a wise one, indeed. To all my professors at Carleton, I say thank you, especially to Dr. Mark Pearcey, Dr. Daniel Preece, Dr. Radha Jhappan, Dr. Kathleen Fitzgerald, Dr. Peter Gose, and Dr. Brian Schmidt, each for impacting my thought and orientation towards society, politics, and economics. And a special thank you goes to Dr. Randall Germain, who provided me with steady mentorship, sage advice, and friendship when I really needed it. Without his influence and enthusiasm towards my views and ideas about political economy, I would not be writing this today. I am also incredibly grateful to all of my friends, teachers, mentors, and others who taught me, directed me and made me the person I am today.

To my family, thank you for believing in me and helping me through these times. I also want to thank my dog, Curie, who is a very, very good girl. And last, but certainly not least, I need to thank my beautiful, amazing, strong, patient, and wonderful wife, Diana Perini, who brough me up when I was down, believed in me when I didn't, who inspired 
and encouraged me to carry on, no matter the sacrifices that she had to make. Thank you, forever and always. Te Amo mucho y tanto, hasta el cielo!

We did it Pollita.

We did it. 


\section{Preface}

I am a survivor of psychiatry. At a different time and in a different place, while wearing the uniform of the Canadian Armed Forces, my request for help with work-related stress led me into a dystopian world filled with paradoxes, gaslighting, deceit, dishonesty, and gross abuses of my dignity and my rights. I was diagnosed, unseen, with a pervasive mood disorder and prescribed medication. I rejected both. I had my freedom taken away from me, I had the facts of my life overridden by the narratives of a disease progression and was under constant threat and duress of physical and chemical restraints. My civil commitment papers listed the reasons for my commitment as 'pressured speech, paradigm shift.' What I was arguing in front of the assessing physician was that I rejected the psychiatric model entirely, refused to be treated under their epistemological and ontological precepts, and argued that the entire system needed a paradigm shift. To him, the suggestion that psychiatry was a system that was failing my fellow service members and needed to change, was delusional.

While committed, I documented every violation of my rights under the Canadian Charter of Rights and Freedoms, relevant acts and statutes, and patient rights provisions. I recorded the interactions I had with nurses and doctors, able to confirm their words and actions when they denied them. When addressing the violations of those rights, I was deemed agitated and irritable, in addition to grandiose, even being accused of having a delusion of being a lawyer in a court room. I was told I said or did things that I certainly had not. Beyond my own circumstances, I watched in horror as those who were hospitalized along with me were abused, infantilized, provoked, manipulated, assaulted, 
isolated, and tortured by those charged with their care, all while supported by a state and government that guarantees their individual rights and humane treatment.

I was told upon my discharge that I would have to do certain things in order to avoid 'ending up back here.' First and foremost, I had to take my medication. Medication that was at a maximum clinical dose that made me nauseous, caused chronic and still occurring tinnitus, that gave me debilitating migraines, that gave me a tremor in my left hand, that dulled my senses, that affected my speech and ability to think. Second, I would have to leave the Canadian Armed Forces (which was fine with me at that point) and resign myself to the fact that I would likely not be able to work full time again and certainly not shiftwork. Third, I was told, as were my parents, that as a highly competent and regarded naval engineering technician in my mid-thirties, I would likely not be able to live independently and would need to be close to them so that they could supervise my treatment and ensure I was taking my medication. Fourth, I was told that I should avoid romantic relationships because I would not be able psychologically handle them, given my pervasive mood disorder. All previous attempts to argue for myself as a sentient and capable individual were operationalized as a symptom of my serious disease: I had a lack of 'insight' into my 'illness.' I simply nodded my head and accepted the narrative that the psychiatrists were writing for me so that I could get out from their clutches.

Once out, showing what my former 'caregivers' would certainly see as a lack of insight, I developed a withdrawal plan and stopped my medication. I got myself legal protection against the psychiatric system through a notarized care directive. I sought assistance from a clinician of my choosing outside of the state/psychiatry and military apparatuses. I moved to a new city in a new province, free from the military, hundreds of 
kilometers from my family, on my own. I enrolled in school. I met a woman. I got married. I worked four jobs at once while completing my bachelor's and then master's degrees, and I have secured long-term, fulltime, high level employment. And this thesis represents a formal and in-depth call for a paradigm shift; the same rejection of psychiatric authority and legitimacy that had me deemed mad in the first place. The way to dismantle the apparatus is to understand the apparatus.

Either one of two things is true: this thesis is nothing more than the ramblings of a madman or psychiatry lacks insight into itself and in the dynamic between psychiatry and subject, the insanity lies with the former and the interests it represents. My experience has led me to conclude that human rights violations are so common to psychiatry because psychiatry does not recognize that they are dealing with human beings worthy of rights and dignity, but only see their patients as diseases requiring control and manipulation in a process of outright subjectification. Psychiatry has just been one extended mass experiment on the effects of poison and authority on living human subjects, all under state sanction and encouragement. When the powerless construct their own reality, it is insanity; when the powerful do it, it is the apparatus.

This thesis is a direct result of my experience and my questions of how and why: how and why could I be treated in such a substandard manner in my own country - a country that is manifest in its guarantee of human rights - a country that I proudly and honourably defended? The answer was not readily apparent, the answer was not simple. But I sincerely believe that the contribution herein goes a long way to answer those questions that were formulated in a dingy ward of a Canadian psychiatric hospital. And I hope that others find answers to those questions through this work, too. 
Imrat (2018), Wipond (2018), Burstow (2015), Rose (2017), and others have been contributors and advocates arguing that there needs to be more survivor-led scholarship in the studies of mental health and psychiatry. It is my sincere wish that this thesis proves to be a worthy entry into the body of literature and can assist in changing a broken and devastating system so that those who need help get help on their terms, according to their values in an ethical, holistic, and truly evidence-based manner. That is what their states and governments guarantee. That guarantee by the state cannot be fulfilled as long as state and psychiatry remain fused through the apparatus, turning suffering individuals into psychiatric subjects. 


\section{Table of Contents}

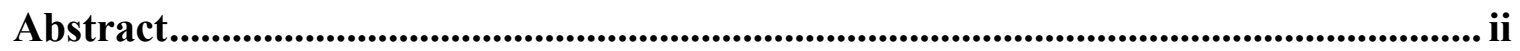

Acknowledgements ......................................................................................................ii

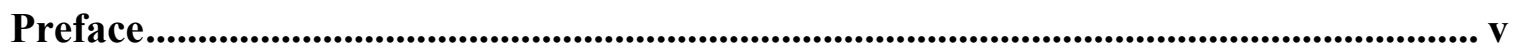

Table of Contents ............................................................................................................................ ix

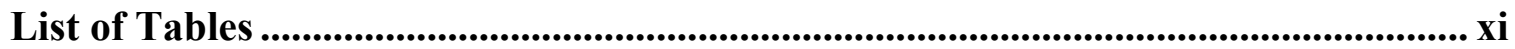

List of Figures...................................................................................................................................... xii

Chapter 1: Introduction ................................................................................................................... 1

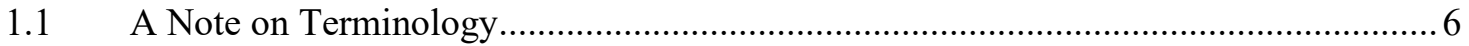

Chapter 2: Background on Critical Psychiatry ................................................................. 9

2.1 Psychiatric Power: Shining a Light on the Shadow of Coercion........................................ 11

2.1.1 Coercion, Compulsion, and Control ............................................................... 11

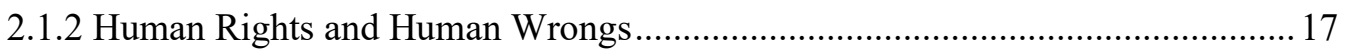

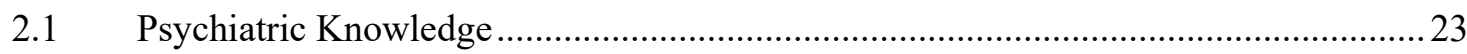

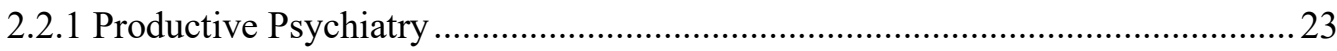

2.2.2 The Knowledge Market - Power, Interest, and the Institutional Corruption of

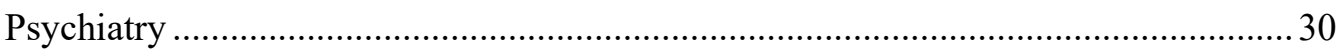

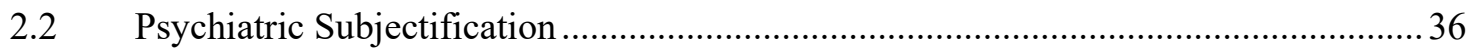

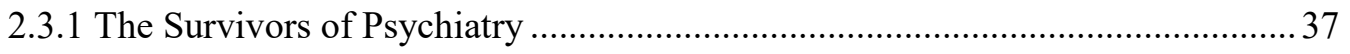

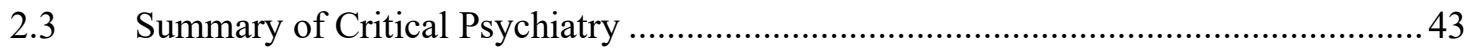

Chapter 3: The State/Psychiatry Apparatus ...................................................................... 45

3.1 The Political Economy of Psychiatry …................................................................. 45

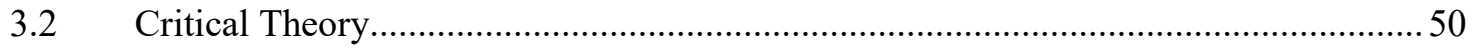

3.3 The Intellectual Foundations of the State/Psychiatry Apparatus..................................53 
3.3.1 Foucault, Governmentality, and Biopower...................................................56

3.3.2 Marx, Gramsci, and Psychiatric Hegemony ..................................................... 61

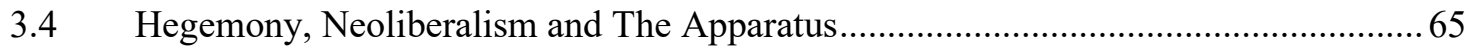

3.5 The Parameters of the State/Psychiatry Apparatus................................................... 70

\section{Chapter 4: The Constitution and Function of the State/Psychiatry Apparatus in}

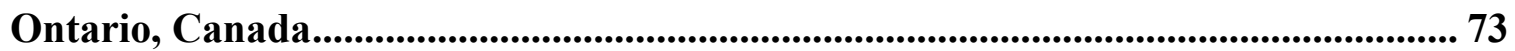

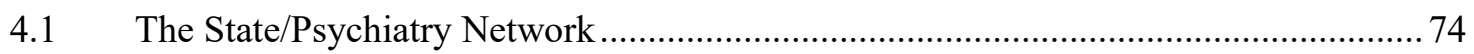

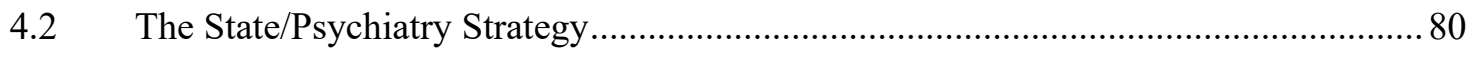

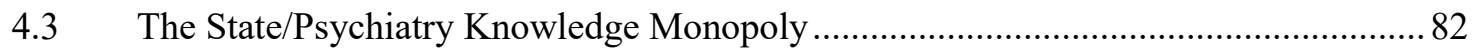

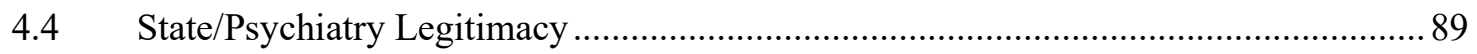

4.5 The State/Psychiatry Apparatus in Summary ................................................................. 94

Chapter 5: Conclusion ................................................................................................................. 96

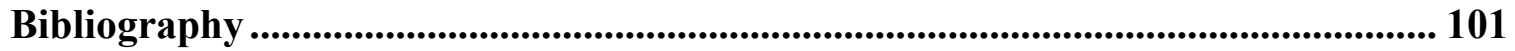




\section{List of Tables}

Table 1: Professional and Guild Associations ......................................................... 84

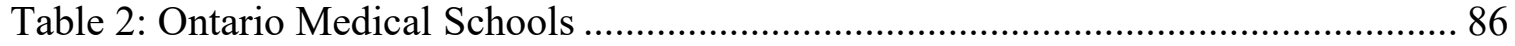

Table 3: Legitimating Acts and Legislation............................................................. 91 


\section{List of Figures}

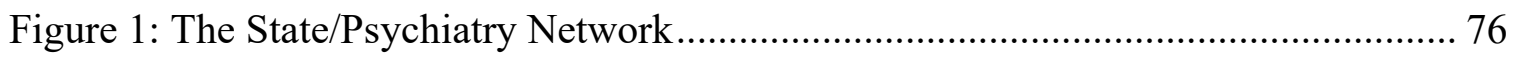

Figure 2: The State/Psychiatry Apparatus in Canada and Ontario ................................ 81

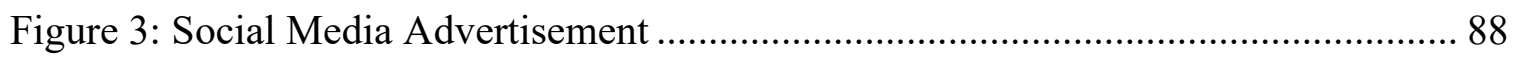




\section{Chapter 1: Introduction}

Mental health stands as a paramount concern for numerous states and governments throughout the world. According to the Center for Addiction and Mental Health (CAMH) (n.d.), mental disorders are the leading cause of disability in Canada and world-wide. The Mental Health Commission of Canada (2016) estimates that 1 in 5 Canadians suffer from mental illness. Furthermore, the CAMH (n.d.) states that "Canada and the world are in the grips of a crisis that ruins health, threatens lives, and hurts economies." The economic costs of mental illness are staggering. Mental illness costs the Canadian economy in excess of $\$ 50$ billion per year (Mental Health Commission of Canada 2016, 1). Globally, it is projected that mental health costs will continue to rise, estimated to reach $\$ 16$ trillion USD by 2030 (Patel et al. 2018). In June of 2017, the United Nations Office of the High Commissioner on Human Rights called for a global revolution in mental health care, concluding that contemporary approaches to the relief of mental distress and treatment of disorders were not working and the evidence bears this out (OHCHR 2017). The number of people diagnosed with a mental disorder has ballooned in the $21^{\text {st }}$ century. A 2001 World Health Organization report (cited by CAMH n.d.) found that, globally, 450 million people had a mental disorder. This number has increased to approximately 1.1 billion as of 2018 (Ritchie and Roser 2018). The political economic importance of such a global crisis is rather evident; that 1 of every 8 people on the planet have a mental disorder is rather significant for the global and state political economies. 
Accordingly, several institutions, formal and informal, have arisen within the mental health sector. Foremost among them has been the institution of psychiatry and its diagnostic model that stresses the medicalization of mental suffering and behavioural anomalies as resulting from a biological cause (Gøtzsche 2015). Since the institutionalization of psychiatry in the middle of the twentieth century through its massive growth and integration into society at large as the de facto and in many cases, de jure, authority on mental health, two puzzling counter-factuals have emerged:

1. That mental health diagnoses have continued to rise throughout the world, particularly in western, neoliberal, capitalist states, both in the sense that there are more classifications of disorders than ever alongside more incidences of individuals being diagnosed with mental illnesses or disorders (Gøtzsche 2015) and that once diagnosed, there is not a curative pathway only treatment through medication (Bortolotti and Widdows 2011; Gøtzsche 2015). According Gøtzsche (2015), “a chemical cure for mental diseases doesn’t exist. Antipsychotics don’t cure psychosis, antidepressants don't cure depression, and anti-anxiety drugs don't cure anxiety; in fact, these drugs can cause psychosis, depression and anxiety, particularly if used longterm [sic] and if people try to get off them" (212). This fact is admitted even within institutions that advocate the biomedical model. As the Mayo Clinic (2019), one of the United States' leading clinical and research hospitals, admits even in advocacy of psychiatric practice, "psychiatric medications don't cure mental illness" (n.p.), but are part of a long-term treatment strategy focusing on symptom alleviation rather than disease eradication. 
2. That there is no scientific evidence that mental disorders or illnesses are caused by any known biological factor (Bortolotti and Widdows 2011; Gøtzsche 2015; Cohen 2016). As the Council for Evidence Based Psychiatry (2014) explains, "There are no known biological causes for any of the psychiatric disorders apart from dementia and some rare chromosomal disorders" and "there are no biological tests such as blood tests or brainscans that can be used to provide independent objective data in support of any psychiatric diagnosis" (2). At best "biology is implicated in mental distress, just as it is implicated in any emotional, physical or mental state that is experienced as either positive or negative...precisely how it's [sic] implicated, and precisely to what degree, we do not really know" (4). There may be a concrete link between biology and mental distress in an etiological relationship but that link has yet to be discovered.

Given these counter-factuals, the question that begs asking is why is psychiatry the dominant approach to mental health, endowed with extraordinary state power over the individual given its problems of validity and efficacy?

The answer to this puzzle can be found in political and economic structures. Psychiatry persists as a political economic institution that is endowed with and reinforces the power of the state over the individual's body and mind while representing capitalist and neoliberal interests. It is this confluence that forms the state/psychiatry apparatus. The state/psychiatry apparatus, which will be defined in Chapter $\mathbf{3}$

This work serves as an exploratory exercise along two lines. First, I seek to establish the problem of psychiatric practice as the primary approach to mental health care by explaining that its epistemological ontological and methodological composition is 
at odds with any claims of scientific practice or legitimate medical care and its power over the individual is equally at odds with conceptions of constitutional, democratic human rights. Once the problems of psychiatry are established, I move onto the significance of psychiatry as unit of political economy proceeding to develop a theoretical explanation for psychiatry's persistence in global, international, state, national and substate political economies. I then focus the theory on the case of Ontario, Canada, a case that represents a neoliberal, capitalist, western political economy that is a constituent and instrument of the state/psychiatry apparatus. In applying the theoretical construct of the state/psychiatry apparatus, it is hoped this thesis can serve as an analytical framework for future analyses of psychiatric knowledge and power and their relations to state, society, and citizens.

The intellectual foundations of the state/psychiatry apparatus lie in the works of Marxist/Gramscian scholars, such as Robert W. Cox, and the works of Michel Foucault and those who followed in his scholarship. Broadly, an apparatus occurs when knowledge and power are consolidated over the living being, producing a process of subjectification. In Chapter 2, I proceed with a background of critical psychiatry, a body of knowledge that is outwardly critical towards psychiatry. This section is organized in line with the knowledge, power, and subjectification that defines the apparatus. This review serves to critique psychiatry as a set of discourses, practices, and policies. Section 2.1 focuses on psychiatric power: the way how that power is operationalized and the consequences of that power on individual human rights. Section 2.2 examines psychiatric knowledge and the way that psychiatric knowledge has a monopoly on mental health narratives and practices through the American Psychiatric Association (APA) and the Diagnostic and Statistical Manual (DSM), followed by the ways that psychiatric knowledge is corrupted 
when financial economic interests enter the equation. Section 2.3 looks at the process of subjectification that occurs through the merger of power and knowledge over the individual through the voices of psychiatric survivors.

Chapter 3 addresses the troubles of psychiatry and accounts for why and how psychiatry continues to enjoy its power and privilege in political economies. Section 3.1 provides an overview of political economy and contextualizes psychiatry as a topic highly appropriate for political economy studies. Section 3.2 provides the template for theory-building developed through Cox's conception of critical theory. Section 3.3 examines the Marxist and Foucauldian foundations of the state/psychiatry apparatus. Section 3.4 takes the synthesis from the previous section as applied to the concepts of neoliberalism, capitalism, hegemony, and their roles in the apparatus. In Section 3.5, the parameters of the state/psychiatry apparatus are identified and explained. This section describes the existential and functional parameters of the apparatus, examining the latter in detail: the state/psychiatry network, the state psychiatry strategy, the state/psychiatry knowledge monopoly, and state/psychiatry legitimation.

Chapter 4 provides a detailed construction of the constitution and function of the state-psychiatry apparatus in Canada, in general, and Ontario, in particular, along the functional parameters defined in Chapter 3. The first section maps the state/psychiatry network in Canada through Ontario, examining the network layers and providing an overview of the organizations, institutions, and agents within the apparatus that transmit, process, consolidate, and operationalize knowledge and power upon the psychiatric subject. Section 4.2 contextualizes psychiatry in Ontario within the apparatus that ensures psychiatry's continued authority in mental health narratives, policies, and 
understandings through the state/psychiatry strategy. Section 4.3 looks at how academia, industry associations, researchers, and institutions seek to preserve the psychiatric knowledge monopoly and its influence in Ontario, and how it emanates from the APA and the DSM; a foreign private industry association. In Section 4.4, the process state/psychiatry legitimation is studied, identifying key legislation, regulation, and public relations that normalize the concept of mental illness to policy makers and the public and rationalize the state enablement of psychiatry's powers over the citizen. The chapter is completed with a summary of the operation and influence of the state/psychiatry apparatus in Ontario and Canada.

The thesis concludes with a discussion of the relevance and significance of the theory presented, an analysis of the limitations of this study and suggestions for further research.

\subsection{A Note on Terminology}

Before proceeding there are a series of terms and concepts that will be used throughout this paper that are in need of clarification and definition. In discussing psychiatry in this paper, I am referring to a set of discourses, practices, knowledges, and claims that emanates from the idea that psychiatry "is the branch of medicine focused on the diagnosis, treatment and prevention of mental, emotional and behavioral disorders" (American Psychiatric Association 2019b, n.p.). The APA is the key player in defining psychiatric boundaries and practices. According to the APA (2019b) within psychiatric practice, "[s]pecific diagnoses are based on criteria established in APA's Diagnostic and Statistical Manual of Mental Disorders(DSM-5), which contains descriptions, symptoms 
and other criteria for diagnosing mental disorders." (n.p.). The APA (2019a) defines mental disorders as "health conditions involving significant changes in thinking, emotion and/or behaviour in addition to distress and/or problems functioning in social, work or family activities" while the term "mental illness refers collectively to all diagnosable mental disorders" and that "mental illness is a medical condition, just like heart disease of diabetes." Given the thin distinction that makes mental illness the aggregate of mental disorders, the term mental illness and mental disorder will be used interchangeably, as is common by expert bodies (see: Mayo Clinic 2019; World Health Organization 2019; US National Library of Medicine 2020 for but a few examples). Essentially, even accounting for the influence of sociocultural and external factors that are accounted for within the APA's calculus, the core ontological claim is that mental illnesses are biomedical in nature. The use of either mental disorder or mental illness will be specifically referring to the APA's conception of the terms as a discursive instrument. In referring to general mental or psychological suffering, the specific terms mental illness and mental disorder will be avoided in lieu of other terminologies.

The APA contextualizes mental illness within the broader concept of mental health which "involves effective functioning in daily activities resulting in [p]roductive activities (work, school, caregiving), [h]ealthy relationships, and the [a]bility to adapt to change and cope with adversity." This definition fits with the use of the term in this paper because as defined, mental health exists independent of mental illness and mental disorders and the psychiatric body of knowledge and practice. 
Neoliberalism will also be a key concept, specifically as a rationale of governance that underpins the state/psychiatry apparatus. Harvey (2005) provides a substantive definition that encompasses the meaning herein:

Neoliberalism is in the first instance a theory of political economic practices that proposes that human well-being can best be advanced by liberating individual entrepreneurial freedoms and skills within an institutional framework characterized by strong private property rights, free markets, and free trade. The role of the state is to create and preserve an institutional framework appropriate to such practices. The state has to guarantee, for example, the quality and integrity of money. It must also set up those military, defence, police, and legal structures and functions required to secure private property rights and to guarantee, by force if need be, the proper functioning of markets. Furthermore, if markets do not exist (in areas such as land, water, education, health care, social security, or environmental pollution) then they must be created, by state action if necessary (2)

Ontario is used as a case study as it has been subject to "neoliberal trends of downloading, privatization and individualization in the areas of mental health policy and the practice of service provisioning, as well as concomitant changes to definitions of mental illness in policy and practice, [that] have produced a new phase of mental health care in Ontario" (Tobin Leblanc Haley 2017, 2). 


\section{Chapter 2: Background on Critical Psychiatry}

Psychiatry endures as the dominant form of knowledge generation and practice in mental health care in Canada, the west and worldwide. This chapter consults a cross-section of contributions to the field of critical psychiatry. This examination will illuminate the deficiencies of psychiatry, justifying the development of the state/psychiatry apparatus in Chapter 3. Embedded in this work is an obvious normative claim that psychiatry, as a source of knowledge and as a practice, lacks evidence for its epistemology, ontology, and methodology and as a result, inflicts incalculable harm on those who fall prey to psychiatric treatment, and to society at large.

Psychiatry possesses a politically privileged status as an institution with powers of detention that often circumvent constitutional rights against arbitrary detention that are innate to most western legal systems. Psychiatry also exists as an economically productive industry in its knowledge generation (Diagnostic and Statistical Manual, clinical practice guidelines) and its corrective methods (psychopharmaceuticals).

Despite its political privilege, increased funding and revenue, position of expertise, and prescriptions for treatment, psychiatry's domination over the field of mental health has produced little in the way of results. The mental health crisis has done nothing but deepen in the half century of biomedicalization of psychological suffering that has taken place under psychiatry's influence (Whitaker 2010a; 2010b).

Resultingly, an emergent countermovement to psychiatry developed. The critical psychiatry movement has its origins in the 1960s and grew into the 1970s with renegade psychiatrists like Szasz (1963), Laing (1991), and Breggin (1975) who all saw psychiatry as a political process and institution as opposed to a medical one. The countermovement 
had some temporary impact, but was neutered through the 1970s to the 1990s as more diagnoses were brought into existence by the American Psychiatric Association's Diagnostic and Statistical Manual, more people were diagnosed with ostensibly biological psychiatric illnesses, and more drugs were developed and prescribed to treat those illnesses. Institutional psychiatry is now a multibillion-dollar industry with considerable political powers over citizens in many states across the globe.

This background in critical attitudes towards psychiatry serves three purposes:

1. To assess the scale of coercive practices embedded in psychiatric practice as it pertains to state facilitation and endorsement and the impact on citizens that are subject to psychiatric treatment and critical discourses towards those practices. In other words, to study psychiatric power.

2. To assess the productive dimension of knowledge within institutional psychiatry as it pertains to the generation and classification of mental disorders and the development and propagation of treatment practices and the financial incentives for. In other words, to study psychiatric knowledge.

3. To examine psychiatry through the lens of those who have been negatively impacted by the administration of psychiatric discourses and practices, facilitated by psychiatric knowledge and power as represented by the psychiatric survivor movement. In other words, to study psychiatric subjectification.

The roles of power, knowledge, and subjectification will underpin this thesis in the development of the theory of the state/psychiatry apparatus. 


\subsection{Psychiatric Power: Shining a Light on the Shadow of Coercion}

Psychiatry is endowed by states worldwide with powers that no other branch of medicine possesses. Psychiatrists can force citizens of states founded upon the ideas of and existence of constitutionally protected human rights into detention and into treatment that violates their bodily autonomy. Psychiatric patients (prisoners in many cases) can also be forced to take harmful drugs with questionable efficacy, forced to undergo electrical shocks, and forced into seclusion for lengthy amounts of time. Examining the rationale for such political privilege alongside the practice of such policy from a critical standpoint illuminates the relations between state, psychiatry, and citizen.

\subsubsection{Coercion, Compulsion, and Control}

Coercion and compulsion are oft-wielded tools of psychiatric practice. Forced treatment is a state-sanctioned and legally endowed practice in virtually every state and jurisdiction on the planet. Szmukler (2015) provides clarification on the difference between and the relationship between compulsion and coercion and their roles in psychiatric treatment. Compulsion involves "the use of force, one hopes always governed by law, to make a person accept treatment that has been refused" (259). As Szmukler notes, forced psychiatric treatment is (hopefully) governed by law. The governing of forced treatment has two elements. The first is that forced treatment is restrained by legal frameworks designed to protect the autonomy of the person in these situations. The second is the very idea of legally sanctioning forced treatment in the first place. Both of these aspects will be examined in subsequent sections. At issue is the idea and practice of forcing somebody (who has committed no crime and has constitutionally protected individual 
rights) to comply to the will of another. In psychiatry, this practice is hidden behind the word 'treatment.'

Compulsion exists as a formal, legal arrangement that forces an individual into psychiatric treatment under the expressed authority of the state. Compulsion is a practice of coercion, which consists of not only legal formal compulsory psychiatric treatment, but a "broader range of treatment pressures" including interpersonal leverage, persuasion and threats (Szmukler 2015, 259), all related to the power asymmetry between psychiatrist and patient. Szmukler describes that psychiatric patients are all subject to psychiatry's "coercive shadow" (259), which is the idea that if one does not comply with psychiatric opinions, that compulsion and forced treatment will be the inevitable endresult. This coercive shadow exists as an implied threat innate in the relationship between every psychiatrist and patient. Threats, implied and explicit, are common psychiatric practice, a threat being a "conditional proposal (if...then...) that, if rejected by the person, leaves him/her worse off according to a moral baseline;" i.e. if you refuse the medication, you will be detained in the hospital" (Wertheimer in Szmukler 2015, 259). That is an incredible level of power granted by the state to psychiatrists over an individual's physical and psychological autonomy, and many of those who have interactions with psychiatry have experienced the way that coercive power is executed over the person.

Despite legal, ethical, regulatory, and procedural injunctions meant to limit the circumstances where compulsory forced treatment may be employed, the practice has increased in frequency in multiple jurisdictions. In general, forced treatment can be carried out in two ways. The first is by institutionalization. In this scenario, the 
psychiatric service user is confined to a hospital or mental health institution until which time treating psychiatrists deem the patient fit to be released. This decision is largely influenced by compliance to psychiatric orders. The second way that compulsion is formally enacted is through community treatment orders (CTOs). CTOs compel individuals to follow drug treatment orders in addition to attending various appointments with social workers, psychiatrists, peer groups, and other points of ordered contact outside hospitals in community-based mental health centres, family homes, and residential facilities; "this may include formal compulsory outpatient psychiatric interventions, but also where individuals are threatened with civil commitment, eviction or refusal of other services if they do not comply with proposed interventions" (Gooding et al. 2018, 10). Even beyond the hospital, psychiatry can take command of an individual's entire being and liberties.

A 2013 review of forced treatment within the United Kingdom's National Health Service found that the practice was on the rise in the preceding years (Bentall 2013). Bentall provides an editorial on the findings of the UK Care Quality Commission's (CQC's) 2013 report into the workings of the Mental Health Act. The findings of the Commission showed that the use of coercion was on the rise in the UK: 2012 saw a 5 percent increase in involuntary detention over 2011 and a 10 percent increase in community treatment orders. Bentall argues that the figures "almost certainly understate the extent to which, in some services, coercion is routine" (n.p.), referring to the report's findings that "many voluntary patients are voluntary in name only, unable to leave locked wards for fear of being sanctioned." This finding is in line with Szmukler's conception of the 'coercive shadow' innate within psychiatry. Additionally, many at-home patients 
on Community Treatment Orders "are subject to informal threats or 'leverage,"” such as losing their housing, benefits or children if they do not comply to medical advice (Bentall 2013, n.p.). The presence of power under the guise of treatment and fear-guided compliance underlays the nature of the relations between psychiatrist and citizen, where the phrase 'doctor's orders' take on an absolutist and literal connotation.

Campbell (2013) provides further analysis of the same CQC report that is the subject of Bentall's editorial. Summarizing the conclusion of the report, he writes that "More people are being sectioned under the [United Kingdom's] Mental Health Act and too many of those detained are subjected to unnecessary restrictions and get too little help to recover, the NHS watchdog reports today" (n.p.). Quoting the report directly, it concludes that while there are indeed some good examples of practice that honour patients' dignity and respect, "some hospitals have allowed cultures to develop where control and containment are prioritized over treatment and care" (n.p.). Further, Campbell reports that the CQC's chief executive concluded that they found "too many instances where people have been restricted inappropriately" (n.p.). Again, the coercive shadow is cast upon voluntary patients, who are "supposedly able to leave [hospitals and psychiatric facilities] at any time" yet the report found that in 88 out of 481 hospital visits conducted by CQC, there was no communication to patients about how they could leave (n.p.). The report further found that practices such as isolation and even taser-use were subject to abuse by facility staff in order to get patients to comply to their will (Campbell 2013). As Campbell writes, the CQC concluded, in rather understated terms that "[p]ractice in some areas ... is a far cry from the policy vision" (n.p). 
In Canada, forced treatment has also seen a marked increase in many provinces, Studies focusing on Ontario (Lebenbaum et al. 2018) and British Columbia (Johnston 2017) have found not only an increase in incidence, but also in the concentration of involuntary hospitalizations and forced treatment. In Ontario incidences of psychiatric hospitalizations have grown, as has the percentage of involuntary hospitalizations as a function of total hospitalizations: 70.7 percent in 2009 compared to 77.1 percent in 2013 (Lebenbaum et al. 2018, 31). The increase in forced treatment is accompanied by many of the same problems of practice experienced in the UK, and in line with Szmukler's findings on the use of compulsion and coercion in psychiatry.

Johnston (2017), in a report for the BC Community Legal Assistance Society, provides a detailed and comprehensive look at the $\mathrm{BC}$ mental health system and its forced treatment regimes. As with the studies conducted in the UK and in Ontario, both the number and concentration of involuntary hospitalizations in $\mathrm{BC}$ has risen. Johnston notes that this fact is in tension with Canada's guaranteed constitutional rights of the individual and that "in many areas of law, the level of state intervention on an individual's liberty and security has generally been decreasing over time and procedural safeguards that ensure fairness when those interventions occur have, correspondingly, been increasing, involuntary mental health detention has followed the opposite trajectory" (23). Yet the compulsive power of psychiatry has grown in western, democratic, constitutional states. This growth has been shrouded under the guise of narratives that position psychiatry as a medical science that only wields its coercive power because it is in the individual's best interests. 
It is often argued by psychiatrists, lawyers, policymakers, police, politicians, and other supporters of forced treatment that it is a necessary evil and that there are no alternatives. Legislation is written with the idea that involuntary treatment is a last resort that is only for the "best interest" of the patient (see, for example, The Mental Act and The Health Care Consent Act of Ontario). Gooding (2018), dismisses this idea, while providing alternatives to coercive psychiatric practice:

Irrespective of whether coercion is viewed as a 'necessary evil' in some emergency situations, it is agreed that coercive psychiatric measures restrict human rights and that support should be framed around the 'rights, will and preferences' (Article 12(4) CRPD) of the individual...International trends in mental health policy and practice have also generated a push to find alternatives to coercive practices. 'Recovery-oriented' and 'trauma-informed' service delivery for example, have become prominent in recent years in many parts of the world. Recovery-orientated practice generally focuses on a person's ability to recover from mental health crises. This approach seeks to avoid what Fisher describes as interventions 'being done to' people. High priority is placed on respect for self-determination. Support is personalized to the capabilities of each individual. Similarly, 'traumainformed' approaches seek to understand the impact of interpersonal violence and victimization on an individual's life and development. In Elliott and colleagues' terms, trauma-informed services are designed to ensure that 'every interaction [within services] is consistent with the recovery process and reduces the possibility of re-traumatization.' Hence, trauma-informed services often promote 'no-force' forms of care and support. (15-16)

The 'necessary evil,' 'no alternatives,' and 'best interests' narratives obfuscate the fact that the very practice of forced treatment can be seen as a de facto human rights violation in and of itself, which in turn spawns an industry rife with human rights violations to the point they are routine at the expense of other treatment methods that respect autonomy, dignity, and human rights. 


\subsubsection{Human Rights and Human Wrongs}

This section looks at the rationalization for the coercive and detentive powers of psychiatry granted to it by states and the tension with the ideas of fundamental human rights that serve as the bedrock for those states' rational-legal authority. Consulting with localized criticism from the province of British Columbia and critical views towards global practice in mental health vis human rights supplied by both the United Nations and the World Health Organization, it will be made evident that psychiatric powers of detention and coercive treatment are irreconcilable with the principles of universal and inviolable human rights.

What is particularly interesting about psychiatry's relationship with human rights is that it is not a secret by any means. The United Nations has issued multiple edicts and reports condemning forced treatment as a human rights violation on the level of torture (Gooding et al. 2018). The Convention on the Rights of Persons with Disabilities, enacted in 2008 by the UN which is binding on States Parties that have ratified or acceded to it, "protects and promotes the rights of all persons with disabilities, including persons with mental and intellectual impairments, and also promotes their full inclusion in international cooperation including international development programmes" (World Health Organization 2013). Despite being ratified by the vast majority of UN member states, including Canada (OHCHR 2020), and put into force, the rights of psychiatric users have been routinely violated.

According to the 2017 Annual Report of the United Nations High Commissioner for Human Rights (UNHCHR), "[t]he right to health contains freedoms, such as the freedom to control one's health and body and the right to be free from interference, 
torture and non-consensual medical treatment" (United Nations, General Assembly 2017,

3). That same report called for a global reorientation of mental health policy that would:

support the full realization of the human rights of those populations, such as the systematic inclusion of human rights in policy and the recognition of the individual's autonomy, agency, and dignity. Such changes cover measures to improve the quality of mental health service delivery, to put an end to involuntary treatment and institutionalization, and to create a legal and policy environment that is conducive to the realization of the human rights of persons with mental health conditions and psychosocial disabilities. (United Nations, General Assembly 2017, 1)

It is the coercive shadow of psychiatry that the United Nations Special Rapporteur on Human Rights was addressing first and foremost in stating that " $[\mathrm{m}] \mathrm{ental}$ health is not merely a health or medical concern, it is very much a matter of human rights, dignity and social justice" (United Nations, General Assembly 2017, 11). The 2017 UNHCHR report was explicit in its condemnation of both involuntary confinement and of forced treatment of those undergoing psychological distress. In the case of involuntary confinement, the report stated:

Forced institutionalization violates the right to personal liberty and security, understood as freedom from confinement of the body and freedom from injury to one's bodily or mental integrity, respectively. It amounts to a violation of the right to live free from torture and illtreatment, and from exploitation, violence, and abuse, and of the right to personal integrity. States parties should repeal legislation and policies that allow or perpetuate involuntary commitment, including its imposition as a threat, and should provide effective remedies and redress for victims. (11)

Pertaining to the forced drugging of those under psychiatric coercion, the UNHCHR report found that:

Many practices within mental health institutions also contravene articles 15, 16, and 17 of the Convention on the Rights of Persons with 
Disabilities. Forced treatment and other harmful practices, such as solitary confinement, forced sterilization, the use of restraints, forced medication and overmedication (including medication administered under false pretenses and without disclosure of risks) not only violate the right to free and informed consent, but constitute ill-treatment and may amount to torture Accordingly, the Committee on the Rights of Persons with Disabilities has called for the abolition of all involuntary treatment and the adoption of measures to ensure that health services, including all mental health services, are based on the free and informed consent of the person concerned. The Committee has also urged the elimination of the use of seclusion and restraints, both physical and pharmacological [emphasis added]. (11)

Despite these explicit condemnations and the ostensible recognition of them by UN member states, particularly by liberal western democracies, there have been little to no limitations on these practices or the state granted powers that allow these practices to become operationalized.

In Canada and in other democratic constitutional states, the power of the state to detain a citizen is tempered with protections for the individual that take priority over the power of the state. Psychiatry possesses powers of detention that contravene that concept. Those determined to be mentally ill are routinely excepted from protections of their rights and liberties. Writing about British Columbia, but representative of the situation as an interstate issue, Johnston (2017) writes:

People who have, or are perceived to have, mental disabilities can be detained in facilities for their benefit or the benefit of others. Detention is an extraordinary and intrusive exercise of state power in any context. But for individuals in mental health detention, the loss of liberty is only the beginning of rights deprivations. Once detained in the $\mathrm{BC}$ mental health system, the detaining facility controls virtually every aspect of your life and your body. You can be denied access to a phone or the internet. You can be denied visitors or the right to go outside for fresh air. Your clothing can be removed by force from your body and you can be denied access to your own clothes. You can be forcibly administered psychiatric treatment, including injections and 
Electroconvulsive Therapy. You can be placed in mechanical restraints that tie you to your bed. You can be put in seclusion. (5)

This passage sets the scene for the report, and indeed psychiatric practice, at large as Johnston identifies a series of methods condemned by the UN in common use in the BC mental health system.

Johnston's (2017) methodology is unique in that the report is structured to chronologically represent each phase in the $\mathrm{BC}$ involuntary hospitalization process, from assessment to intake to appeals to discharge to the post-experience impacts on those detained by the BC system. It is representative of the totality of the functional layers and parameters of the state/psychiatry apparatus that will be explained in Chapter $\mathbf{3}$ and applied in Chapter 4. The research includes statistical data, legal analysis including interviews with lawyers who represent psychiatric detainees in $\mathrm{BC}$, process mapping, policy analysis and interviews with stakeholders. Johnston's findings present a system overrun by abuses of power, substandard and undignified treatment, and human rights violations at virtually every point of interaction between citizen and psychiatry.

The path to involuntary treatment begins with a psychiatric assessment. In most cases, that is done after an individual is presented to a hospital. In some cases, the person presents themselves voluntarily, in others they are brought by a family member or friend, and in others they are brought in by the police. In the case of police-initiated assessments, Johnston (2017) found multiple instances where the initial detention by police did not meet the legislative and regulatory criteria, let alone the subsequent psychiatric assessments that resulted in an involuntary hospitalization both in $\mathrm{BC}$ and in Canada. 
Physicians and police, as agents of the state, are to be held to a standard of care and respect for the individual. Their functions extend beyond medicine and security in mental health legislation as they are also tasked with representing the individual's interests vis their constitutional rights. This balancing act between figures of state authority and guarantors of individual liberties often tilts towards the authoritarian side. As Johnston (2017) notes:

When physicians examine individuals to decide whether they meet the criteria for detention pursuant to the Mental Health Act, they are acting as administrative decision makers on behalf of the state. Section 10(a) of the [Canadian Charter of Rights and Freedoms] provides that on detention, everyone has the right to be informed promptly of the reasons for detention. The certificates that physicians complete to enforce detention pursuant to the Mental Health Act cannot simply contain vague or general references to the statute's criteria. The certificates must provide sufficient application of the legal criteria to the facts of the individual's circumstances to permit the individual and any other person on review to understand the reasons why the decision maker concluded the criteria were met. (27)

Johnston includes an entire appendix in her report that includes commitment certificates that are illegible, improperly filled out, have only one sentence, and describe situations that do not even come close to satisfying the legal conditions of forced treatment. But they had both the individual's name (even if misspelled) and the requisite psychiatrists' signatures.

Despite the right to representation upon detention enshrined in the Canadian constitution, psychiatric detainees are regularly deprived of this right. Combining this lack of legal representation with the habitual paucity of legal justification for detention already mentioned, the initial interactions between psychiatry and citizen are fraught with violations of one's constitutional and human rights. Johnston (2017) found that 
psychiatric detainees were often denied legal representation for a variety of reasons. At the forefront of this problem is a lack of legal aid funding for mental health detainees, despite being qualified to receive it. Johnston writes that in the 2008-2009 fiscal year there were 191 requests for legal aid representation from entitled that were refused due to funding shortfalls (10), which only worsened over time:

As the number of individuals detained in $\mathrm{BC}$ continued to increase and the funding to the Mental Health Law Program remained frozen, the number of detainees denied representation rose every year for several years. By the 2015-2016 fiscal year, detainees who were entitled to legal aid were refused representation 639 times. (10)

When appealing their detentions, individuals who are denied representation are left with a choice between two poor options. They could either represent themselves at a review tribunal, throwing themselves in an administrative court of law without any legal advisor, or they could adjourn to a later date until they were appointed a legal representative, which would prolong their detainment (Johnston 2017, 10). Not only were the detainees subject to violations of their bodily autonomy and dignity, not only were their rights violated by psychiatrists ignoring safeguards in the detainment process, but their guaranteed right to legal representation along their only available path to recourse in the form of an appeal tribunal was obstructed due to their socioeconomic status.

Beyond the abuses of process and representation reported by Johnston (2017), detainees were subject to a series of abusive practices by psychiatrists and psychiatric staff during their hospital stays. Among the abuses suffered by detainees were prolonged isolation, physical restraints without cause, physical harm from staff and other patients, verbal attacks from staff and other patients, restricted communication with family, friends 
and legal representatives, forced removal of clothes (often by the opposite gender), unsanitary conditions, and financial harm resulting from detention.

Psychiatry is marked by its shadow of coercion. That shadow casts a pall over the idea of patients' rights in a way made explicit in Johnston's (2017) report. The practices condemned by the $\mathrm{UN}$ as examples of human rights violations, equivalent in some cases to torture, were omnipresent throughout detainees' experiences in British Columbia (and elsewhere in Canada). Canada is not a developing or authoritarian state, but a liberal, constitutional democracy. Yet the power of the Canadian state is vested into psychiatry as an industry and that power is yielded in irresponsible ways that result in gross human rights abuses as a matter of daily fact in Canadian psychiatric facilities. Those abuses have real effects on real people, often leaving them traumatized and worse off than before their hospitalizations.

\subsection{Psychiatric Knowledge}

Psychiatry exists not only as a medical profession in a clinical setting, but as an industry of knowledge production. Through research, publication, the DSM, CPGs, public relations, academia, and other channels, psychiatric knowledge is vast and all encompassing in mental health narratives. This section looks at the way that produced knowledge leads to commodification of illness and institutional corruption in psychiatric discourse and practice.

\subsubsection{Productive Psychiatry}

Psychiatry is productive, not in its ability to provide effective and meaningful treatments to real and empirically observed illnesses, but in its ability to produce power in political 
economic terms. Its existence is bolstered by an-ever-increasing commodification of illness in western liberal capitalism, which has diffused through the channels of globalization. The arrangement of psychological distress and abnormal behaviours into categories of disorders, illnesses, syndromes, and diseases has been driven by the interests of industrial psychiatry, which has increasingly aligned with the interests of pharmaceutical companies.

To understand what a mental disorder is, it is necessary to understand how they are 'discovered' and diagnosed, which means understanding the Diagnostic and Statistical Manual of Mental Disorders, currently in its fifth edition (DSM-V). The DSM offers a broad definition of the term "mental disorder" The DSM is the dominant methodology of psychiatric diagnostics in the west and globally. Published by the American Psychiatric Association, "[t]he Diagnostic and Statistical Manual of Mental Disorders is the handbook used by health care professionals in the United States and much of the world as the authoritative guide to the diagnosis of mental disorders" ("DSM-5 FAQ" n.d.). The DSM is developed, updated, and published by the APA at irregular intervals by committee and an eventual conference vote (Whitaker 2010a). If enough psychiatrists vote 'yes' a new disorder is created out of thin air.

Whitaker and Cosgrove (2015) explain the link between the DSM and the commercial and political interests of psychiatry and pharmaceutical companies: "[w]ith the publication of DSM-III, the APA, as a guild, had dominion over three "products" in the medical marketplace: diagnosis of mental disorders, research into their causes, and the prescribing of psychiatric medications....[f]rom a commercial perspective, the APA had a need to promote this new disease model to the public (27-28). They further explain 
that the narrative supplied by the APA about its scientific and medical rationale to the public was in fact secondary to guild self-interest, both financial and political:

Although touted for its scientific and medical motivations and results, the DSM's primary function was assuring the power and profitability of the APA and psychiatry and its pharmaceutical partners. By insisting that all disorders in the DSM were illnesses, the APA could now expect that insurance companies would pay for the treatment of nearly everyone who came to a psychiatrist's office, regardless of the person's problem. The APA, with its new diagnostic manual, had helped the insurance companies differentiate "between those who have mental disorders and those who simply have a problem" by asserting, in essence, that those who had a problem...were "ill." (24)

The impacts on industrial psychiatry all went to further psychiatry's power over mental health research and policy. The DSM sold a tale of scientific reliability and validity whereby psychological suffering was caused by biomedical illnesses akin to cancer or diabetes. But that tale, like most, involved a lot of bending of reality to the whims of the storyteller.

The DSM has come under fire since its iteration from critical, ethical, and antipsychiatry movements for its shortcomings concerning its scientific legitimacy as a valid diagnostic device of biomedical conditions. After the publication of DSM-IV and especially after the DSM-V, criticism came from APA insiders, psychiatrists, social scientists, academics, politicians, patients, researchers and even the American National Institute of Mental Health (NIMH). The former director of the NIMH, in announcing a pivot in research funding away from the DSM, had this to say about the DSM:

While the DSM has been described as a "Bible" for the field, it is, at best, a dictionary, creating a set of labels and defining each. The strength of each of the editions of DSM has been "reliability" - each edition has ensured that clinicians use the same terms in the same ways. The weakness is its lack of validity. Unlike our definitions of ischemic heart disease, lymphoma, or AIDS, the DSM diagnoses are based on a 
consensus about clusters of clinical symptoms, not any objective laboratory measure. In the rest of medicine, this would be equivalent to creating diagnostic systems based on the nature of chest pain or the quality of fever. (Insel 2013)

An even more scathing critique is offered by Dr. Allen Frances, who was the lead editor of the DSM-IV. Frances assails the validity of the diagnostic approach offered by modern psychiatry, seeing the very concept of a mental disorder as nothing but farce: “there is no definition of a mental disorder. It's bullshit. I mean, you just can't define it...these concepts are virtually impossible to define precisely with bright lines at the boundaries" (Greenberg 2010). Frances, in an interview (Rubin 2018), also related the ever-expanding borders of the diagnostic thresholds to the financial incentives provided by pharmaceuticals. This has led to a situation where the DSM is easily and consistently misused:

...my concern about DSM-5 was that the experts doing it were given just the opposite instructions; to take the diagnostic system more as a blank slate and to be creative...And if I've learned anything during these 40 years I've worked on DSM's, it's that if anything can be misused, it will be misused, especially if there's a financial incentive. And pharma, the big drug companies, have a tremendous financial incentive in making sure that every DSM decision is misused by expansion, so that people who are basically checked well are treated as if they're sick. They become the best customers for pills. And drug companies have become experts in selling the ill to peddle the pill. So, I was very concerned the DSM-5 would have the negative effect of opening the floodgates even further to what seems to me to be fairly wild diagnosing, excessive use of medication, especially in kids, but also in adults and geriatric populations. (n.p.)

Essentially, the very concept of mental disorder or mental illness is on thin epistemological ground and the ontology and methodology are by extension and 
consequence, equally tenuous. This problem of validity combines a built-in financial incentive to misuse the labels and expand the diagnostic capture of psychiatry.

Despite all the criticisms, the reach of psychiatry has expanded throughout society with each edition of the DSM. This is reflected in the expansion of the "diagnostic creep" (Moynihan, Doust, \& Henry in Cosgrove et al. 2018) of the DSM itself. The first edition of the DSM identified 106 mental disorders in 1952, while the DSM-V defines 374 disorders (Davies in Cohen 2016, 2-3). This 300 percent increase in disorders has been outpaced by the rate of diagnosis of debilitating mental illnesses in the United States between 1955 and 1997, which saw a 600 percent climb (Whitaker 2010a, 7). Even more startling is that, according to Whitaker (2010a), between 1997 and 2007 there was a 3500 percent increase in the diagnosis of debilitating mental disorders in America's youth (7). By every account, psychiatry is like an octopus, whose tentacles not only grow but also multiply in number allowing psychiatry to catch ever-increasing numbers of people in its grip:

In sum, DSM-5 - from a commercial perspective-will provide a diagnostic rationale for treating more children with an antipsychotic; more teenagers and adults with a stimulant; more menstruating women with an SSRI; more people with behavioral quirks with an SSRI (since hoarding and skin picking are seen as obsessive conditions); more grieving individuals with an SSRI; more teenagers and other young adults seen as "prepsychotic" with an antipsychotic; and more forgetful older folks with a drug of a type yet to be determined. This is not to say that this is the APA's intent. The point, as made earlier in this chapter, is that there were economies of influence present during the development of DSM-5, and this manual will further enable the APA to play handmaiden to industry. (Whitaker and Cosgrove 2015, 110)

By positioning themselves alongside other medical specialties, psychiatrists were legitimated through the DSM in a way that the Freudian, psychoanalytic approach that 
preceded biomedical psychiatry could not. The medicalization of human suffering had other benefits for the APA and the psychiatric industry:

Other new financial opportunities that arose from the publication of DSM-III were easy to see. The APA, with its insistence that the 265 disorders were diseases, had asserted a new authority over research into those ailments. If psychiatric problems were psychological in nature, then psychologists and other nonphysicians could easily compete with psychiatrists for grants from the National Institute of Mental Health to study such difficulties. But if such problems were discrete diseases, then research would focus on identifying their underlying pathologies and on developing treatments for the symptoms of these diseases, which was research that physicians could be expected to lead. (Whitaker and Cosgrove 2015, 24-25)

The reorientation of psychological suffering into an illness or disease model had another benefit for psychiatrists. As medical doctors, in contrast to psychologists and other forms of mental health workers, psychiatrists could do one thing that the others could not: prescribe drugs.

In modern psychiatry, the treatment for the 'diseases' created by the DSM is almost always a pharmaceutical intervention. According to Greenberg (2013), pharmaceutical sales of psychiatric drugs are a seventy billion US dollar per year industry. Yet, the data on the success rate of drugging those experiencing mental distress demonstrate that not only is the practice ineffective, but it is in fact harmful, making patients less healthy (Gøtzsche, Smith, and Rennie 2013; Gøtzsche 2015). Gøtzsche (2015), in a cross sectional and longitudinal study of clinical research data, finds that psychopharmaceutical drugs are, in all but acute and exceptional situations, ineffective (performing no better than placebo); that studies have been corrupted by design, by skewing of the data, and by suppression of findings; by a disproportionate influence of conflicts of interest between researchers and financial ties to the pharmaceutical industry 
and that industry's political and economic might. Furthermore, he finds that side effects have been minimized or ignored and that the drugs offered as a solution do more harm to patient outcomes and overall wellbeing than good (Gøtzsche 2015). As a result, psychiatry has been called the "drug industry's paradise” (Gøtzsche, Smith, and Rennie 2013, 250) and "psychiatric research is predominantly pseudoscience...reliable research constantly tells us a very different story to the fairy tale that leading psychiatrists want us to believe in (Gøtzsche 2015, 14). Moncrieff (2008) attributes the role that insurance billing had in influencing psychiatry's pivot from psychoanalysis to a categorical, biomedical model, which aided psychiatry's increased profile and revenue. The DSM provided a solution to that problem and opened the doors to the pharmaceutical industry, research dominance, and narrative monopolies at the expense of science, evidence, human rights, and individual and social well-being in order to further the economic and political self-interest of the APA and the psychiatric industry:

The American public may now understand that psychiatric disorders are "real illnesses," and that the DSM is a scientific guide to distinguishing such illnesses, but, as can be clearly seen, that is an understanding that arose from APA publicity efforts, and not from a faithful accounting of scientific findings. Most of the diagnoses in the APA's manual have yet to be "validated." (61)

Just like many other situations in the past and present of political economy, the meeting of institutional power and profit led to the prioritization of industrial interests over the well-being of citizens and society and to the institutional corruption of psychiatry. 


\subsubsection{The Knowledge Market - Power, Interest, and the Institutional Corruption of Psychiatry}

Psychiatry, as an industry endowed with power over citizens by states, seemingly should be ruled by a strong ethical foundation, in the tradition of Hippocrates. Yet, the 'do no harm' element of the ancient Greek physician's oath is routinely violated by psychiatry's very nature and that harm is further exacerbated by corruption within psychiatry. The economics of psychiatry and its entanglement with pharmaceuticals make psychiatry fertile ground for corruption. Combining the finances of psychiatry with its political privilege and power over people leads to an industry is institutionally corrupt. The position of psychiatry in the mental health conversation is assured not because psychiatry is scientifically sound, producing effective treatments and cures. The position of psychiatry is assured because of its prioritization of power over evidence that its disorders and treatments lack efficacy and validity.

Despite the fact that the scientific problems of psychiatry are rather obvious when the industry is put under scrutiny, psychiatry continues to dominate mental health care to the point of monopoly. The reason for this is that:

Key players of nonevidence-based psychiatry include pharmaceutical companies and professional societies, both of which are capable of manipulating the evidence base to serve their own interests...through manipulation of the research agenda by drug companies, and concomitantly through the selective reporting of efficacy and safety data. (Cosgrove et al. 2018, 5-6)

Cosgrove et al. (2018) and Whitaker and Cosgrove (2015) argue that psychiatry is overwhelmed by institutional corruption. Unlike individual corruption, where individuals behave in unethical and illegal ways that violate trust for their personal fulfillment, 
institutional corruption is not focused on 'bad apples' but on 'bad barrels' (Cosgrove et

al. 2018; Whitaker and Cosgrove 2015):

...institutional corruption refers to the systemic and usually legal practices that cause the institution to act in ways that undermine its public mission and effectiveness, and ultimately weaken public trust in the institution. There is a "bending" of the original mission, which results from the normalization of behaviors that compromise truthseeking. Such practices and behaviors may arise when there are financial incentives at work that encourage the members of the institution to regularly behave in ways that undermine the institution's integrity and its capacity to fulfill its public mission. Moreover, the leaders of the organization will likely be unaware that their institution has become "corrupted," and protest against those who have come to see their institutional behavior as being at odds with the organization's intended mission. (Whitaker and Cosgrove 2015, 6)

The APA claims that their mission is to provide "humane care and effective treatment for all persons with mental disorders" (American Psychiatric Association in Whitaker and Cosgrove 2015, 6). As seen in previous sections, psychiatry's practices are neither humane nor effective. And at the heart of the inhumanity and ineffectiveness is pharmaceutical money: "researchers and clinicians continue to be involved in relationships that create clear conflicts of interest between physicians' duty to their patients and their financial arrangement with pharmaceutical companies, whose primary goal is maximizing profit" (Cosgrove et al. 2018). The vulnerability to corruption is particularly attenuated for psychiatry for a web of reasons explained by Cosgrove et al. (2018):

One of the reasons for the increased concerns regarding psychiatry's crisis of credibility is that there is no blood test or scanning technique to determine when a patient has a psychiatric disorder. As a result, the diagnosis of when human emotions, thoughts, and behaviors are no longer considered normal, but instead pathological and requiring treatment, is subjective, culturally bound, and highly variable. Indeed, the absence of biological markers for psychiatric conditions makes 
psychiatry more vulnerable to industry influence than other medical specialties. Moreover, industry has been able to co-opt the lack of biological markers to its own advantage, resulting in a derailment of psychiatry's public health mission (Cosgrove \& Wheeler, 2013). For example, industry has played a major role in developing and reinforcing the "pharmaceutical imaginary" (see, e.g., Jenkins, 2010) i.e., understanding emotional distress in terms of neurotransmitter dysfunction. The pharmaceutical imaginary serves commercial and guild interests but undermines an appreciation for the socio-political context of distress and concomitantly, social determinants of health. Within this framework, depression, anxiety, PTSD, etc., become known as discrete disease entities to be treated somatically by medical experts, leaving the social order untouched. Interventions are thus aimed at the intrapersonal (and often neurochemical) level, not the policy or sociopolitical level (2).

The pharmaceutical imaginary dominates at the expense of other evidence-supported research into mental suffering due to the financial advantage that psychiatry has by virtue of its relationship with pharmaceuticals. Despite empirical research that shows strong associations between psychological problems and trauma, abuse, and socioeconomic factors, the overwhelming research agenda and policy influence of psychiatry persists. Rather than acknowledge the clear etiological relationship between psychosocial experience and direct research towards the way that experience influences mental health, "these experiences are set up as inherently disordered or pathological and so are inconsistent with continuum models of functioning" to be diagnosed and drugged (Allsopp et al. 2019).

The institutional corruption model explains the way that educated and wellmeaning people who become psychiatrists can condone and engage in discourses and practices that are inhumane and scientifically unsound. Whitaker and Cosgrove (2015) examine the 'economies of influence' that have corrupted industrial psychiatry: the APA's own guild interests, the influence of pharmaceutical money on the APA, and the 
influence of pharmaceutical money on academic psychiatry. The publication of the DSM-

III in 1980 marked the point where the APA went all-in on the biomedical model of mental illness and the response by pharmaceutical companies was immediate and sustained:

The disorders were to be diagnosed based on characteristic "symptoms," a model that other medical specialties, when faced with illnesses of unknown causes, had long used. The public was encouraged to think of mental disorders as "diseases," and very soon, with this concept in mind and the arrival of new psychiatric medications on the market, the use of these drugs soared. In the United States, spending on psychiatric drugs increased from around $\$ 800$ million in 1985 to more than $\$ 40$ billion in 2011, evidence of how the diagnosis of mental disorders and the prescribing of psychiatric medications have dramatically expanded since the publication of DSMIII (Whitaker and Cosgrove 2015, 9).

In the same timeframe, the APA's guild interests were sustained by massive public relations campaigns and lobbying efforts and funded by pharmaceutical companies.

Virtually every APA function and conference included pharmaceutical sponsorship and product awareness seminars with other perks for attending psychiatrists, including trips, gifts, and lucrative consulting positions (Whitaker and Cosgrove 2015). By the turn of the $21^{\text {st }}$ century the APA's annual meeting was a huge revenue generator, with pharmaceutical companies paying $\$ 50,000$ each to sponsor a seminar or symposium (34).

As Whitaker and Cosgrove write:

With the pharmaceutical companies paying for the symposiums, filling the exhibit hall with their exhibits, and funding social activities, the annual meeting became the APA's most profitable activity. Meeting revenues rose from $\$ 1$ million in 1980 to $\$ 3.1$ million in 1990 , and then revenue tripled again in the 1990s, reaching \$11.3 million in 2000 . Four years later, the APA's meeting revenues hit $\$ 16.9$ million, producing a profit of $\$ 9.8$ million for the APA that year. The APA found that it could turn to pharmaceutical companies for money to fund its public affairs campaigns, its political lobbying efforts, and other 
special projects. Pharmaceutical companies could also be tapped to pay for fellowships for young psychiatrists. Drug companies were bringing new products to market, and they provided funding to the APA to mount campaigns to "educate" the public about depression and anxiety. One of the first such campaigns was funded by Boots Pharmaceuticals, which sponsored 100 workshops on depression around the country. (34-35)

The APA increased their annual revenue from $\$ 10.5$ million in 1980 to $\$ 24.9$ million in 1990 , and then doubled again in the 1990s, hitting $\$ 50.2$ million in 2000 and growing to $\$ 65.8$ million in 2008 (36). The marriage between pharmaceuticals and psychiatry was consummated and thriving. The APA's guild interests and the pharmaceutical industry's influence on the APA are compelling economies of influence on the corruption of psychiatry.

The final economy of influence identified by Whitaker and Cosgrove that has corrupted psychiatry is perhaps the most nefarious. The role that pharmaceutical money has had in psychiatric research has flooded society with dangerous, addictive, ineffective, life-altering, and, in many cases, fatal chemicals parading as medicines.

There are numerous examples of drug companies manipulating the results of clinical trials. For example, Cosgrove et al. (2018) write that vortioxetine, a serotonergic antidepressant, was approved in the United States and Europe by regulators after manufacturer Lundbeck/Takeda suppressed trial results that showed the drug had limited efficacy compared to placebo, in addition to questions regarding its safety:

...[the] published reports, written by researchers supported or employed by Lundbeck/Takeda, do not raise the concerns noted above regarding efficacy, nor do they acknowledge that there are inadequate short or long-term data to support the claims made about safety and tolerability. It is noteworthy that every author in all of the published short term RCTs had significant commercial ties to the manufacturer, well beyond research funding (e.g., they were employees, participated on advisory 
boards, and/or had received consulting monies or honoraria). These commercial ties are cause for concern in light of the discordance between the independent and industry affiliated analyses of the trial data. (4)

Whitaker and Cosgrove (2015) document similar situations involving Prozac (70), Xanax (69), Zoloft (74), and a host of atypical antipsychotics (82). Gøtzsche (2015) found more instances of this type of manipulation and suppression of trial data and the fatal consequences that result, as drug companies massively underreported the incidence of suicide by trial participants for drugs such as sertraline, fluexotine, paroxetine, with selective serotonin reuptake inhibitors, in general (55-64).

There is a common pattern to the way that psychiatric drug trials unfold that is often corrupted by the financial motivations of psychiatry: As Cosgrove et al. (2018) explain:

In the current climate, academic researchers can have significant and long-lasting ties to drug manufacturers and still believe they are immune to explicit or implicit bias if they disclose these ties. Publishers and journal editors can have financial ties to the same drug companies and publish these studies without concern that their judgment may be compromised. However, there are decades of research demonstrating that scientists, like all of us, cannot overcome guild interests and implicit bias - reviews of research studies have found that commercially funded trials are up to four times more likely to report industry friendly results compared to trials conducted by independent researchers. Although all medical specialties have grappled with questions of undue industry influence, this problem has been a pernicious one for psychiatry. For example, there is clear evidence of publication bias in psychotropic drug trials (i.e., negative trials are not published) and negative trial results are written in a way that conveys a positive result (e.g., reporting on secondary rather than primary outcome measures; Turner, Matthews, Linardatos, Tell, \& Rosenthal, 2008). Because the vast majority of clinical trials in psychiatry are often designed, interpreted, and written by industry funded researchers (or even employees of pharmaceutical companies), the potential for the corruption of the scientific evidence base looms large. De JesusMorales and Prasad (2017) offer the following powerful analogy: "It would be as if military manufactures provided their own analyses of 
foreign-policy and made recommendations about when to wage war." (3)

The consequences to society and individuals are immense. Many people have lost friends, family members, and other loved ones simply because their loved ones did what they were told and took the drugs that their doctors prescribed. Those drugs were marketed as effective relief for psychological distress, but the truth told another story. As Gøtzsche (2015) writes, there is an obligation to do those who have died justice:

We owe it to those who died because of a greedy, criminal and fraudulent drug industry, assisted by overly industry-friendly drug regulators and corrupt psychiatrists, to tell some of their stories. A thousand deaths are a faceless statistic. But there are real people behind the numbers and when we describe what happened to real people, other people tend to take notice. (61)

Psychiatry has become a corrupted institution that has, as Whitaker and Cosgrove (2015) convincingly argue, put its own political and economic enrichment above its mandate to provide humane and evidence-based care. Over and over since its existence, the APA has fought for its own survival at the expense of the survival of those for whom psychiatry is supposed to help. Paraphrasing Gøtzsche’s (2015) book title, psychiatry is both deadly and in denial.

\subsection{Psychiatric Subjectification}

A psychiatric diagnosis has more consequences to an individual beyond the accompanying treatment plan prescribed. The attachment of a psychiatric disorder to a person also creates a new identity - the mentally ill person. By mentally ill person, it is important to note that the concept of mental illness, without known biological etiology, 
only exists as a concept and as a subjective diagnosis. This section explores the impacts

of being a mentally ill person.

\subsubsection{The Survivors of Psychiatry}

Shifting focus from the institution of psychiatry and those that assure its power within states to those who have suffered under psychiatric 'care' provides context for the nature of the gross power inequality between psychiatrists and those under their control. The stories and voices of psychiatric survivors will be highlighted to provide a first-person perspective on the toll of psychiatric practice.

Survivors of psychiatry have become a strengthening and increasingly organized voice of political dissent over time. Adame (2014) explains that:

The psychiatric survivor movement is an international political activist movement primarily made up of organizations dedicated to fighting for human rights in the mental system... [t] hose who embrace the designation of "psychiatric survivor" have experienced abuse and/or oppression in the mental health system, and thus have survived psychiatry itself rather than a diagnosis of mental illness per se. In grassroots advocacy and peer support groups, psychiatric survivors support one another as they heal from iatrogenic trauma, and also engage in activism efforts, creating and operating alternatives to traditional mental health services. (457)

From individual and grassroots efforts, a multitude of regional, national and international survivor organizations have been established since the 1970s, such as Mind Freedom International, The Hearing Voices Network, the National Association for Rights Protection and Advocacy, and the National Empowerment Center, among others (457). In addition to survivor groups, critical psychiatry organizations and journalists have created platforms for research, writing, and publication of survivor advocacy efforts (457). 
Psychiatric survivors are providing their voices to the mental health conversation with increasing frequency and volume.

Survivors have reported that they have been "held with little justification, denied access to a lawyer, put in solitary confinement, physically restrained - and forcibly treated - essentially indefinitely" (Wipond 2018, 5). Gooding (2018) writes that "[c]oercion in psychiatry and the fight against forced treatment are two of the main topics in the mental health service user/ psychiatric survivor movement worldwide" (23). The survivor movement is made up mainly of those who have been subject to psychiatric compulsion and coercion, deprived of their freedoms and liberties, and drugged against their will. Often, the experience is described as being worse than experiencing the initial distress that led to their treatment in the first place:

Indeed, a compulsory admission to hospital is often experienced as traumatic, sometimes leading to the same kind of post-trauma symptoms experienced by victims of assault or life-threatening events. Of course, many psychiatric patients have previously experienced physical and sexual abuse, bullying and other kinds of victimization that is often why they develop psychiatric problems in the first place so coercion by services adds to a burden of adversity that is already too great to bear. It also damages relationships between patients and services, often leading to greater reluctance to seek psychiatric help during future crises. (Bentall 2013, n.p.)

Beyond the individual harms that accompany the very experience of being made an involuntary of psychiatry, the 'necessary evil' argument that psychiatry relies upon is premised upon the idea that compulsory treatment is in the patient's best interest and essential for their future recovery. Yet, a review of studies conducted looking at the results of involuntary treatment finds that the evil may not be necessary at all: 
... involuntary measures in psychiatry can have adverse effects: For example, closed-door settings may increase the risk of escalation and aggression, involuntary measures may be (re)traumatizing for the patients, and decreased therapeutic atmosphere and patient-therapist relationship may have lasting detrimental effects on a patient's motivation for treatment. Furthermore, even though involuntary measures like compulsory admissions may be well accepted by a majority of the public, they constitute a source for stigmatization of psychiatry and its patients with all accompanying detrimental effects. In addition, involuntary measures may not always provide the intended protection their use is based on: For example, it has been shown that treatment in a closed-door setting does not necessarily have the previously assumed positive effects on aggression, suicidality, and absconding. (Arnold et al. 2019, 1)

Even in instances where in retrospect, individuals agree that they did need to be hospitalized, "they will often maintain their negative view of the use of coercive care and continue to feel that they were subjected to unfair, disrespectful and/or humiliating treatment" (Berge et al. 2018, 19). In addressing their hospitalizations, a group of psychiatric survivors from the Greater Toronto Area in Ontario agreed that "the trauma that they were most concerned with stemmed not from difficult life situations (e.g. abusive relationships) but from mistreatment and/or abuse within a system that creates oppression under the guise of "help" ... [a]s one participant explained, "If you force someone, you are infringing on someone's rights" (Mental Health "Recovery" Group 2009, 20). For those who have sought help in the past, they have come to find that psychiatry does not offer it, but instead psychiatry offers coercion, compulsion, and control.

Survivors have also criticized the biomedical model of mental distress that is the etiology underlying psychiatric knowledge and practice. The Mental Health "Recovery" Group (2009) found that survivors in Ontario made note that the socioeconomic realities 
of their lives were all but ignored by their psychiatrists and other points of contact in the psychiatric system. Survivors made note of the fact that housing, poverty, drug addiction, employment, stress, physical health, past trauma, abusive relationships and other socioeconomic factors were at the forefront of their suffering but were disregarded by their 'treatment teams.' Attempts at redress or to contact advocates were often ignored or exacerbated their situation. Wipond (2018) explains the situation in Canada:

...most major mental health organizations in Canada do not actually care about or support the civil rights of psychiatric patients. And this is not news to anyone who has followed these issues closely over the years. Even as they claim to be trying to reduce "stigma," most mental health organizations are run by mental health professionals and others who have long campaigned, behind the scenes, to support a regime of uncontested psychiatric power and control. This regime (often unquestioned by trusting members of the public who've never personally encountered this system up close) makes it easy to subject virtually anyone unfortunate enough to get labelled with a "mental disorder" to incarceration and forced treatment. And this is always paternalistically done "for their own good," no matter how many times they may tell us our "help" is not helping them. (6)

The options for somebody detained against their will are limited. As noted previously, it is incredibly difficult for psychiatric detainees to access legal representation in the first place and so-called mental health advocacy organizations often advocate the practices of the industry or the institution, not the rights of the patient.

Psychiatric survivors are often left with more than just the trauma and disappointment associated with their compelled experiences with psychiatry. They are often left to deal with debilitating iatrogenic effects resulting from psychiatric medications, as "virtually all psychiatric drugs can cause cognitive and memory problems, anxiety, panic and 'paranoia"' (Shimrat 2018a, 7). Survivors also reported experiencing hemorrhaging, osteoporosis, diabetes, organ damage, seizures, obesity, 
neurological disorders, heart attacks, strokes, and other debilitating physical effects (7-8).

Despite the fact that all of these side effects experienced by users are known and listed by drug regulators, survivors of psychiatry are often either not informed of these potential consequences, or the side effects are minimized by psychiatrists (Mental Health "Recovery" Group 2009).

Perhaps worse than the physical side effects are the neuropsychological ones. Tardive dyskinesia is another commonly reported side effect where the individual exhibits behaviours such as shuffling from poor balance, constant chewing, extreme twitches, tics and spasms (Shimrat 2018a, 7). Survivors have also highlighted the ways that psychiatric medications have led to cognitive and psychiatric decline, often causing the very symptoms that the drugs were meant to treat including mania, psychosis, and hallucinations (Shimrat (ed.) 2018). In these cases, rather than acknowledge the side effects, psychiatrists often either increase the dosage or prescribe different or additional medications (Davies 2018). When patients express a desire to get off their medications, psychiatrists often refuse to assist in the matter with the threat of coercion and compulsion looming in the background.

Many psychiatric survivors have reported that they were put into a situation where taking the medications that they were prescribed made their conditions worse than before they were treated. With psychiatrists often hostile to their requests to cease medication, many survivors have had to stop on their own, without medical supervision (Shimrat (ed.) 2018). Along with the suppression of information regarding side effects, survivors are often denied the information that quitting psychiatric medications produces its own set of debilitating side effects, most prominently, "the horror of 'withdrawal psychosis' - a 
surge of unusual thoughts, emotions and behaviour triggered by coming off the drugs too rapidly - which psychiatrists then blame on the underlying "disease" and use as a pretext for increased drugging" (Shimrat 2018a, 7). These actions by psychiatrists constitute just another violation of psychiatric survivor rights, even in the case of patients who were voluntary and compliant at the beginning of their interactions with psychiatry, as psychiatrists are denying their patients the right to informed consent. With the foreknowledge of the dangers of psychiatric medication, many users would not have taken the drugs in the first place (Shimrat (ed.) 2018).

Another consequence of being labeled with a mental illness is the role that stigma plays in the-post psychiatric social reality lived by survivors. The fields of critical disability studies and mad studies operationalize the stigma as represented by the biases of saneism (or sanism)/mentalism. Saneism/mentalism refers to "systemic discrimination against people who have been diagnosed as, or are perceived to be 'mentally ill'" contrasted with the "ways in which 'sane' people - those who have never been 'psychiatrized' or perceived as 'mentally ill'—have access to privileges that mad people do not" (Wolframe 2013). Leblanc and Kinsella (2016) define saneism as "a deeply embedded form of discrimination and oppression affecting those who experience madness... a system of thought underpinning the practice of epistemic injustice" (61) which is found in the "psychocentrism" of psychiatric knowledge "wherein pathologies are taken to be rooted in the mind and/or body of the individual, rather than the product of social relations, structures and problems" (Rimke in Leblanc and Kinsella 2016, 61). Sanism effectively privileges psychocentrism at the expense of psychiatrized subjects. Wolframe recounts her experience in the Ontario psychiatric system and her self- 
liberation, outlining the way that she was psychiatrized and the sanesim she faced afterward with the label of mental illness in her pursuit of a $\mathrm{PhD}$ and in life, writing "people have not always treated me as though I am reasonable, trustworthy, safe to be around, and capable of taking care of and making decisions for myself, because they knew I had been diagnosed as, or they perceived me to be mentally ill" (5). The impact of these biases unfold as a host of material consequences as "people with mental illness labels have historically been forcibly removed from society and even today are often excluded from or marginalized in the labour force, political institutions, the academy, and activist circles" (Tobin Leblanc Haley 2017). The dominance of psychiatric knowledge goes beyond the realm of psychiatry and feeds into other socio-cultural experiences and settings of the psychiatric subject, constantly feeding social stigma and discrimination towards those who had to interact with psychiatric institutions.

The fact that the lack of psychiatry's scientific validity is actively suppressed from patients and from the public by psychiatry is highly problematic given psychiatry's political power over individuals and presentation as medical science. Psychiatry's ostensible medical standing is the mechanism that leads to untold suffering of psychiatric survivors, material and social, yet it is a standing that is based on deception and lies and motivated by industrial and guild interests at the expense of patient care and scientific evidence.

\subsection{Summary of Critical Psychiatry}

Psychiatry occupies a unique position politically. This is fueled by its economic capacities. It is an industry that has exorbitant powers over citizens. These powers have 
been repeatedly reinforced and supported by states despite a body of critical works calling into question the very justification for such powers - namely, expertise. Critical psychiatry has identified the failures of psychiatry in observing basic human rights via the use of coercion in psychiatric practice. This has been further reinforced by studies conducted by local and global reviewers, alongside mandates that states restrict psychiatry's powers of detention and coercion over citizens. Psychiatry has managed to emerge with a monopoly on knowledge as it concerns mental health and the actions of states and governments in developing policy. With the amount of wealth that psychiatry generates combining with the political power it possesses, corruption is rampant within the industry from the production of disorders to the prescription of drugs to the detention of individuals. The aforementioned factors coalesce within a neoliberal rationale in western capitalist states that individualizes and commodifies sickness to the benefit of not the individual, but to the productive sectors and corporations that profit of the suffering of others and the states and governments that enable it, producing the state/psychiatry apparatus. 


\section{Chapter 3: The State/Psychiatry Apparatus}

The question under examination is why and how it is that psychiatry operates as the authority on mental health discourse, practice, and policy in spite of serious problems of scientific reliability and validity, efficacy, and ethics. In the previous chapter, the myriad problems of psychiatry were laid bare. That psychiatry operates with state sanction and privilege in view of its failings of validity, legitimacy, and efficacy necessarily leads to questioning psychiatry's continued dominance of mental health discourses, practices, and policies. The latter area is of particular interest in the next section, especially given the reliance on what governments call evidence-based policy making. Searching for the answer to this question leads to the realm of political economy. If psychiatric disorders have no scientifically established biological etiology, if psychiatric treatments often do more harm than good, if the industry is institutionally corrupt and financially compromised, and if its practices have been equivocated with torture, then the answer cannot be found within the rationality of biomedical science, democratic rights, or evidence-based policy and psychiatry's domination must be explained otherwise; through the theory of the state/psychiatry apparatus.

\subsection{The Political Economy of Psychiatry}

The theoretical literature concerning the political economy of psychiatry and mental health is rather patchy. Unlike many problems of global concern, the particularities of mental health approaches have eluded many streams of political economic theory. Yet the interest of and application of political economy theory to psychiatry as an industry and articulation of power is obvious. 
The study of and theories of political economy are subject to a diverse and intersectional sets of ideas, lenses, and approaches. Political economy intersects with a variety of social science disciplines that inform and contribute to the pedagogy and theory-building of the discipline: economics, anthropology, sociology, economics, political science, international relations, philosophy, and history (Paquin 2016; Caporaso and Levine 1992). Despite vast differences in opinion in what political economy is and how it should be studied, there is near-universal agreement that political economy emphasizes power relations behind the social and political structures of production and distribution.

Like many concepts in social sciences, the exact definition of power is contested within political economy literature. For the purposes and context of this work, at its most bare, power is well-defined by Max Weber. Although translations from the original German vary, Weber defined power as the (prob)ability of one actor (either individual or collective) to affect its will over other actors despite resistance (Weber in Walliman, Tatsis, and Zito 1977, 231). This definition is implicit in all formulations and manifestations of power from a conceptual level across political economy theory and studies. Whether the role of markets in exploiting the worker, the great powers over the lesser, or the government's rule over the individual's body, mind, and life itself is sourced as the affectation or delivery system of power, the fundamental point remains that power will cause individuals and groups to behave in ways and engage in activities that they would not necessarily do if given absolute free will. Foucault represents a different orientation towards power that claims that power is everywhere and coming from all directions (Foucault 1978) lacking structure and agency and hierarchy. Yet 
Foucault also wrote that "where there is power, there is resistance, and yet, or rather consequently, this resistance is never in a position of exteriority in relation to power" and that "these points of resistance are present everywhere in the power network." (95). He further writes "a plurality of resistances, each of them a special case: resistances that are possible, necessary, improbable; others that are spontaneous, savage, solitary, concerted, rampant, or violent; still others that are quick to compromise, interested, or sacrificial; by definition, they can only exist in the strategic field of power relations" (96). Within Foucault's conception, despite the conceptualization of power being something diffuse and unfixable in a locus, he also recognizes the relational aspects of power and resistance. Whether Foucault terms it as such, this resistance must be towards something and that implies a rejection of the will of agents of power as found in Weber's conception. Even in Foucault's rendering power is instrumentalized through the actions of institutions and agents over others subjectified by that power.

It is important to note that power, nor the consequences of its organization, distribution, and execution are not in and of themselves malevolent, but the asymmetries that exist in power relationships are of utmost interest to scholars, writers, and researchers working within political economy. In Weberian terms, the asymmetries of power distribution create a division of those with power and those subordinate to powerholders, the rulers and the ruled, in relationships of domination which "implies a minimum of voluntary compliance [by the subordinate actor], that is an interest (based on ulterior motives or genuine acceptance) in obedience" to the orders of the powerful (Weber 1978, 212). These relations are self-reinforcing in that "when dominance continues for a considerable period of time, it becomes a structured phenomenon, and the forms of dominance become the social structures of society" (Gingrich 1999). 
Various scholars approach the study of power in different ways under different categorical labels. The first approach of interest, Marxist political economy finds the locus of power in markets and the organization of material production by classes in a capitalist system. Descending from Marx, Gramscian and neo-Gramscian scholars (such as Robert W. Cox) see power as more subtle and diffuse through societal, material, ideological and cultural structures involving the relationship between state, society and order that produces hegemony (Paquin 2016, 108-33). The second approach to political economy guiding this chapter, Governmentality studies, was founded by Michel Foucault and conceptualizes modern power as biopower: governmental power over the body and very life of the individual aggregated into apparatuses and affected through technologies of rule (Foucault and Gordon 1980; Gordon 1991; Teghtsoonian 2009; Springer 2012). Political economy as a discipline and framework of analysis of social phenomena is highly concerned with power as a fundamental unit of analysis.

Power and its effects on material distribution and action is at the heart of most approaches to studying and theorizing political economy. Psychiatry is an institution, body of knowledge, and set of practices that wields and exercises a considerable amount of power in that psychiatry and its agents (professional associations, lobbyists, collaborative industries, public relations firms, policy writers) are able to exercise their will over those who resist through formal and informal mechanisms of compulsion and coercion which are enabled and empowered by state and government sanction through laws, statutes and regulations. Beyond the role of power in psychiatry, the industry has political economic relevance through its interactions with other areas of the study 
political economy such as production, trade, and law. These factors make psychiatry an appropriate topic of study from the perspective of political economy.

The relations of psychiatry and state are of essential interest. The state is a political unit with the recognized exercise of sovereign power over a specific territory and polity combined with the social forces - ideas, institutions, and material capabilities (Cox 1981, 136), that are aggregated, disseminated and organized through forms of government, in view of competing social, political, and economic interests as determined by the discursive and material realities of a particular time and place.

Within the field of political economy itself there is not a wide range of literature specifically focused on psychiatry or mental health as compared with other subjects of scholarship. However, even with the relative paucity of theoretical literature in relation to other issues, there are indeed some good works on the topic from both political economy scholars and those that have intersectional interactions with political economy. Additionally, there are some broad applications of political economic theory at a general level as psychiatry operates within state policy and administration with a manifest interest in two of political economy's key domains: wealth and power. As to be expected, given the overtly critical viewpoint towards psychiatry as a neoliberal political economic institution herein, the majority of the theoretical literature presented below that will provide the bedrock for the development of the theory of the state/psychiatry apparatus emanates from critical discourses and studies towards psychiatry by scholars that represent critical theories of political economy and interdisciplinary works in the social sciences. 


\subsection{Critical Theory}

Critical theories of political economy encompass a cross-section of approaches and intellectual outlooks. Perhaps the most well-known formulation of critical political economy theory was provided by neo-Gramscian theorist Robert W. Cox. In his seminal contribution, Social Forces, States and World Orders: Beyond International Relations Theory, Cox (1981) formulated an approach to employing theory and engaging in theory-building that can be applied to not only international relations and international political economy but also at state and substate levels. Cox rejected the orthodoxy of the 'state is a state is a state' approach, arguing that "state and civil society are so interpenetrated" that they cannot be distinct, leading to his conceptualization of the "state/society complex" as a fundamental unit of political economic analysis (126).

Cox's view recognizes that the actors that influence political economy at all levels of political economic activity are vast, diverse, and represent a plurality of societal influences on state activity and behaviour in a reinforcing and mutually constitutional relationship. The state/psychiatry apparatus proposed herein is premised upon this state/society dynamic: societal forces (industrial, educational, medical, institutional) interact with state interests (wealth, law, and good order) defining the relative distribution of power (detention, punishment), which creates discursive and intellectual social narratives and modes of practice that serve to reinforce both state and societal interests, including the political and the economic.

The most oft-quoted passage from Cox's article states succinctly that "[t]heory is always for someone and for some purpose" (128). That is to say that in the social sciences, theory carries with it a perspective specific to a "social and political time and space" (128). Within this context, Cox identifies two approaches to theory-building. The first is what Cox terms problem-solving theory, representing traditional or orthodox 
approaches to social theory, taking "the world as it finds it, with the prevailing social and power relationships, and the institutions into which they are organized, as the given framework for action" (128). Critical theory, on the other hand, seeks to challenge the status quo of political, economic, and social institutions, standing "apart from the prevailing order of the world and [asking] how that order came about" (129). Resultingly, critical theory eschews positivism, universality, and neutrality in favour of comprehensiveness, historicism, and normative arguments (Paquin 2016). The thesis being presented is an attempt to answer how the prevailing order that regulates the discussion and practices surrounding psychological problems emerged and persists.

In Cox's formulation, critical theory, "does not take institutions and social and power relations for granted but calls them into question by concerning itself with their origins and how and whether they might be in the process of changing. It is directed towards an appraisal of the very framework for action, or problematic which problemsolving theory takes as its parameters" (129). The previous chapter presented the problematic issues associated with the current order of institutions, social forces, and power related to psychiatry and mental distress. Cox further explains that critical theory is representative of the social and political complex as a whole, rather than as separate parts, distinguishing it from orthodox or problem-solving theory. According to Cox, in practice, "critical theory, like problem-solving theory, takes as its starting point some aspect of a particular sphere of human activity" (129). In the case of this work, the starting point is the conceptualization and alleviation of mental and psychological distress at a political and practical level through the institution of psychiatry and its relations to the state.

The results of critical theory contrast with the results of problem-solving theory in that the "problem-solving approach leads to further analytical sub-divisions and 
limitation of the issues to be dealt with" (129). This is particularly obvious in the way that state policy reflects the interests of the psychiatric industry in that the solution to the continued failure of the psychiatric biomedical model has been to further categorize, classify, quantify, and treat mental suffering as a medical phenomenon. At the state policy level, it is essentially taken as fact that mental illnesses exist while psychiatric and pharmaceutical treatments are taken for granted as solutions to the problem.

This section, employing the critical approach to the problems of psychiatry and mental health will, in Cox's words, lead "towards the construction of a larger picture of the whole" in order to "understand the processes of change in which both the parts and the whole are involved" (129). This chapter will define, develop, and conceptualize the state/psychiatry apparatus as an explanatory theory as to why and how psychiatry continues to dominate practices, policy, and people where mental health is concerned.

There is a wide body of critical literature emanating from outside of, or at the border of, political economy concerning psychiatric power and mental health policies and practices. A thorough accounting of the critical discourse towards the specifics of psychiatric knowledge and practice was presented in the previous chapter. The problematization of psychiatry is an exercise in critical theory as defined by Cox in that problematization seeks to challenge the status quo in seeking out 'the silences' in policy and dominant political discourses (Bacchi 2012). Yet, the problematization of psychiatry does not answer the question of interest (why psychiatry continues to dominate), but rather makes the necessity of asking the question evident. In the face of such an obvious question, the answer is surprisingly elusive to many scholars, professionals, and politicians. But that is because, as Cox, Gramsci, Foucault, Agamben, Cohen, and others will assist us in seeing, they are trying to solve the problem of mental illness, rather than critique the institution that argues such a thing exists in the first place. 
Cox provides a general framework for utilizing critical theory as an analytical tool and provides a template for theory-building. Cox built his theory of the state/society complex and world orders by engaging with his critical predecessors, namely Marx and Gramsci, building upon ideas that Cox saw as contemporarily and socially relevant, while being mindful of the limitations of their theoretical work as being defined by each of their times and places. In a similar vein, the state/psychiatry apparatus will be built by incorporating Marxian and neo-Gramscian critical theory, in addition to ideas grounded Michel Foucault's works on governmentality, biopower, and the apparatus.

\subsection{The Intellectual Foundations of the State/Psychiatry Apparatus}

Foucauldian scholarship is the most directed towards the problems of psychiatry. Foucault developed a variety of concepts that he applied to his own genealogy of psychiatry (Foucault 1988) alongside the broader idea, under his theory of governmentality, that there exists biopower as a "neoliberal technology of rule" or "power" (Foucault and Gordon 1980; Foucault et al. 1991; Foucault 1995; Gordon 1991; Gutting and Oksala 2019; Teghtsoonian 2009). Foucault's concepts have been applied to mental health policy analysis (see: Teghtsoonian 2009) focusing on the neoliberal political rationale as a driver of policy generation. There also exists a theory of psychiatric hegemony that situates psychiatric dominance within Gramscian and Marxist concepts of hegemony (see: Cohen 2016; Cohen, Carl I. 1997). What I am proposing is a theoretical marriage between the two approaches to illuminate the state/psychiatry apparatus, the construction of which is inspired by the conceptualization of the state/society complex by Robert Cox and the apparatus by Michel Foucault.

Despite areas where Foucauldian theory and Marxist/Gramscian theory are in tension (Daldal 2014; Springer 2012), the two approaches have many similarities that 
allow for their combination. In his writings on governmentality, Foucault prioritizes historical dynamics as do Marx, Gramsci, and Cox. Foucault rejected the structural limitations of historical materialism, turning towards a historical genealogical approach (Gutting and Oksala 2019). Both approaches also adopt a critical disposition to established power structures and are firmly planted in Cox's conception of critical theory.

The tension between the approaches itself and "the rupture that exists in current theorizations of neoliberalism is to at least some degree framed by a false dichotomy between those studies that have been influenced by Foucault in emphasizing governmentality, and those studies that foreground ideas of hegemonic ideology, drawing influence from Marx" (Springer 2012, 133). Daldal (2014) traces the tension between Foucault and post Marx thinkers like Gramsci to the conceptions of power developed by each school. To Gramsci, power is rooted in ideology, while Foucault sees power as omnipresent. Gramscian power resides in relations between the rulers and the ruled, in "the complex social network-hegemonic forces-within which an individual realizes himself already generates power. Once a social group is able to modify the ensemble of these relations and make it "common sense", it is creating a hegemonic order" (Daldal 2014, 149). Contrasting Foucault with Gramsci, Daldal writes, "Foucault's basic difference from Gramsci is that the latter saw power relations in terms of binary oppositions (such as leaders and the led, rulers and the ruled etc.). For Foucault though, power, as well as the resistance it generates, are diffused and not localized in some points" (149). However, this fundamental difference can be accounted for and reconciled when considering the analytical approaches of Foucault and Marxist scholars. 
Both Foucauldian and Marxist lenses are concerned with "Machiavellian 'relations of force"' (Daldal 2014, 149). The respective focuses of Foucauldian and Marxist approaches concerning relations of power answer different questions concerning the nature of those relations. Foucault eschewed the ideological aspect of power because he is generally concerned with the "how" of power," (Daldal 2014, 161) and concentrates on "bringing to light power relations, locating their position, finding out point of applications and methods used" (Foucault, in Daldal, 161)... Foucault's "research on power has a goal: to decipher the way man is being turned into a subject through power relations" (161). Foucauldian political economy explains how power is generated, communicated, executed, diffused, consolidated, and resisted.

To answer the question of why power is arranged in this way, Marxism provides a method. The ideological struggle between classes and the capitalist drive for increasing commodification and accumulation provides the fuel for the Foucauldian fire. Arguing that Foucault and Marx can work in synthesis, Marsden (2014) advocates a postFoucauldian Marxism which argues that "Marx explains the 'why' of power and the law of motion of society and Foucault explains the 'how' of power and the microphysics of society" (24). When examining the respective ideas and discourses in Foucauldian and Marxist thought, the differences between the approaches fall away, attributing the tensions to both the questions being answered by each lens and Foucault's "deliberate choice of avoiding such [Marxist] terminology [which] is linked to his wish to break up with the "all pervasive" para-Marxist approaches of his era"...but "when he talks about this "totalizing" power of the State which tries to produce a peculiar regime of truth, 
Foucault almost duplicates Gramsci's theory of Hegemonic civil society and Althusser's Ideological State Apparatus" (Daldal 2014, 162).

It is in view of the similarities between Foucauldian and Marxist theory that the theoretical development of the state/psychiatry apparatus will proceed. Adopting Marsden's conception of Post-Foucauldian Marxism, the next sections will conceptualize, define, and apply the theory of the state/psychiatry apparatus.

\subsubsection{Foucault, Governmentality, and Biopower}

Governmentality is an approach to political economy that heavily incorporates philosophy, history, and sociology into its analysis. Michel Foucault is the founder of the theory, which states that government is not just a thing, but a practice. Government is a manner by which the powerful shape the behaviour of those under their rule. Foucault (1991) described this government-as-practice as "the conduct of conduct" (5).

Governmentality forwards the idea that rule and power are defined throughout space and time by various "political rationalities" (Teghtsoonian 2009, 29). The contemporary political rationality is neoliberalism which is carried out with "advance liberal technologies" of rule that allow those in power to "forego coercion or direct control in favour of seeking to forge an alignment between the self-interested choices of individuals and the goals of those who govern" (29), which is in line with Weber's definitions of power and domination. The modern political rationality and technologies of rule have coalesced in a form of "economic government" (Gordon 1991, 12). This form of government takes capitalist market rationality as an embedded feature of rule and 
decision making, in the overarching modern episteme, or discursive formation, of neoliberalism (Gutting and Oksala 2019).

Foucault wrote extensively about madness and the resolution thereof over time. As Bacchi (2012) references Foucault, in the problematization of madness, Foucault is concerned with:

how madmen were recognized, set aside, excluded from society, interned, and treated; what institutions were meant to take them in and keep them there, sometimes caring for them; what authorities decided on their madness, and in accordance with what criteria; what methods were set in place to constrain them, punish them, or cure them; in short, what was the network of institutions and practices in which the madman was simultaneously caught and defined. (3)

Foucault sees psychiatry as an institution "endowed with limitless power" (Foucault and Lagrange 2006). Serving as an institution of discipline and punishment on behalf of the state, psychiatry was legitimated through Foucault's knowledge/power structure that was concerned "with the way which power is a precondition of the development of a body of knowledge and how knowledge could, in turn, function as power" (Moncrieff 2008, 13). Through this construct, psychiatry is elevated to the status of an "inaccessible authority without symmetry or reciprocity" under the power derived from the idea of "medical authority... which functions as power before it functions as knowledge" (Foucault and Lagrange 2006, 3). This medical authority is supported by the state under an over arching "neoliberal political rationality" as an "advanced liberal technology of rule" (Teghtsoonian 2009, 29).

Foucault regards neoliberalism as a rationality of governing "connected with specific technologies of power," and "is not understood just as an economic doctrine, but as a governmental form that is directed toward specific objectives, regulates itself 
through continuous reflection, and, essentially, aims to ensure that capitalism works" (Gutting and Oksala 2019, n.p.). Psychiatry exists as a political institution and a technology of power that assists in capitalist functions within the neoliberal rationality. The synchronization of psychiatry with state/government interests consolidates and enhances the power of both entities in the form of the state/psychiatry apparatus. Neoliberalism is marked by "a normative and analytic emphasis on the individual, and a preference for private sector funding and delivery of services" alongside "[a]dvanced liberal technologies of rule [that] are underpinned by a reconceptualization of the social in economic terms, so that individuals come to be understood as rational, calculative actors" (Teghtsoonian 2009, 29). When the interests of rational individuals fail to align with the political rationality of those who govern, the coercive and controlling mechanisms of rule reappear in institutions of discipline and punishment (Foucault 1995). This type of rationality is innate to the industrial psychiatric paradigm, with the spectre of coercion underpinning the asymmetric relationships between state-backed psychiatrist and citizen.

The rule of law is another technology of rule that is fused knowledge and power, which is used to facilitate 'legal' forms of coercive discipline and punishment. The rule of law facilitates other technologies of power predicated on discipline and punishment such as psychiatry, creating a perpetuation of the generation and facilitation of power, knowledge and technologies: "It is a double process, then: an epistemological 'thaw' through a refinement of power relations; a multiplication of the effects of power through the formation and accumulation of new forms of knowledge" (Foucault 1995, 224). In essence, the foundation of knowledge is shaped by power and vice versa in a reinforcing 
and constitutive relationship while power relations are executed through technologies of rule which lead to further knowledge and power aggregation alongside new technologies of rule in a positive feedback loop. This dynamic is evident in the increasing power that a private industry association, the APA, has had in monopolizing knowledge production and affecting governing structures. The DSM has become codified and canonized knowledge in state laws, statutes and regulations pertaining to mental health, at the expense of any other forms of analysis or remedy of psychological distress (this will be elaborated upon in subsequent sections).

Foucault spent much time studying what happens at the fracture point of the harmony of interest between the individual and government and the operationalization of the knowledge-power relationship embedded in those relations. Governmentality theory was developed in direct reference to psychiatry as a disciplinary and punishing technology of rule and institution of corrective coercion. In his book Madness and Civilization (1988), Foucault traces the history of treatments towards the mentally distressed up to the contemporary era. Applying his theory of governmentality, he generates a "genealogy of psychiatry" (Foucault and Gordon 1980, 64). He finds that as psychiatry emerged as the science of the mind, claiming a positivist epistemology grounded in empirical evidence that mental distress is an organic and biological concern, its legitimacy and power increased in the eyes of society. Foucault counters the very idea that psychiatric knowledge represents 'objective' knowledge, finding that "the alleged scientific neutrality of modern medical treatments of insanity are in fact covers for controlling challenges to conventional bourgeois morality" (Gutting and Oksala 2019, n.p.). 
Psychiatry trades on the image of the psychiatrist as the authority and possessor of scientific knowledge, which in turn leads to the granting of more and more power to psychiatrists: “As positivism imposes itself on...psychiatry, this practice becomes more and more obscure, the psychiatrist's power more and more miraculous, and the doctorpatient couple sinks deeper into a strange world" (Foucault 1988). The evolution of this relationship is marked by a change in thought towards madness, moving away from the idea that people are holistic entities endowed with a soul and that madness results from the vices of modernism: "[i]n [contemporary] psychiatry, the insane are regarded less and less as casual ties of progress and modern living, and more and more as the detritus of social evolution" (Gordon 1991, 37). This transition is represented in contemporary applications of governmentality to mental health policy, where the neoliberal and economic rationale are omnipresent in legislation, statutes, and regulations.

Current governmentality scholars have maintained a focus on psychiatry as a technology of rule. It is argued that the modern approach to mental health is "individualizing and depoliticizing [and] fails to address the negative impacts of a broad range of government policies and on people's well-being" (Teghtsoonian 2009, 29). The individualizing of one's mental stress is a convenient construct that allows for the dismissal of social forces that are generated in tandem with governmental policy, thus reinforcing the knowledge-power relationship and technologies of rule within the neoliberal rationality. As Teghtsoonian notes, modern governmental policy analysis and development concerning mental health care in western nations "proliferate individualized understandings" of mental distress that fail to address the presence of "systemic social and economic inequities" (29) thereby "marginalizing the socio-political" (34) in favour 
of perpetuating the illness of the individual; writ short, psychiatry allows governments to blame the individual for the problems of society.

This leads to a situation where mental health policy is dominated by the biomedical model of individualized distress. Furthermore, power is vested in psychiatry, not for its validity or care outcomes, but for its role in the perpetuation of neoliberal rationality and the interests of economic government. As Gutting and Oksala (2019) summarize, "[i]n short, Foucault argued that what was presented as an objective, incontrovertible scientific discovery (that madness is mental illness) was in fact the product of eminently questionable social and ethical commitments." Psychiatry, on its surface presents itself as an instrument of effective and ethical medical care. A deeper look uncovers an institution and instrument of political economic power.

\subsubsection{Marx, Gramsci, and Psychiatric Hegemony}

Marxist scholars have also interrogated psychiatry along economic and capitalist dimensions to identify its utility to both states and general capital interests. The obvious focus of the economic dimension of psychiatry is the pharmaceutical returns from psychiatric drugs. With pharmaceutical sales approaching $\$ 100$ billion USD per year (Greenberg 2013), Moncrieff (2008) links the increasing dominance of the biomedical model of psychiatry to economic interests, writing that "in the 1970 s medical insurance agencies started to cut back on the amount of psychiatric treatment they would reimburse and it became more important for psychiatrists to be able to quantify and justify what they did" (50), which they did through increasing complexity and efficacy. This follows with Foucault's conception of the discursive power of psychiatric knowledge claims 
wrapped up in the guise medical legitimacy through the DSM and pharmaceutical treatments. Once the industry became 'legitimate' in the way that other branches of medicine are, the concurrent growth of psychiatry and psychopharmaceuticals only concentrated and enhanced the power of psychiatry and its presence in state policy and into society at large.

In addition to seeing the DSM as a tool that commodifies mental suffering, Cohen (2016), uses a Gramscian analysis to interpret the influence of psychiatry, settling on a concept of psychiatric hegemony, defined as:

the expanding ideological power of the psychiatric discourse within neoliberal society. I present here my core rationale for taking a Gramscian approach to understanding this discourse as "hegemonic," that is, an all-encompassing form of knowledge which works to naturalize and reinforce the norms and values of capital through professional claims-making. (69)

Showing accord with Foucault, Cohen sees the ideational power of psychiatry as the source of its legitimation as hegemonic force. Cohen further views the commodification of mental illness as a factor that is increasingly "more important to the production, circulation and management, in State and civil society" (Parker 2014, in Cohen 2016, 35) that helps "legitimize ruling class ideology through their practices and constructed discourse" (Cohen 2016, 69). This is achieved through the domination of knowledge generation as found in the form of the DSM and the setting of academic and industrial research agendas.

Cohen (2016) provides a rather comprehensive literature review of Marxist attitudes towards psychiatry and mental health. Cohen argues that Marxist scholarship and critical scholarship at large is concerned with the expansion of psychiatry in 
influence and power vested in its ever-growing list of disorders and diagnoses. There is a particular focus on the economic impact of pharmaceutical sales on psychiatry, mainly "the influence of pharmaceutical corporations...on the construction of new categories of disorder and the promotion of drug solutions for those disorders" (Cohen 20164 ). Cohen elaborates on this concern writing that "critics point to the 69 per cent of psychiatrists responsible for the development of the latest edition of the DSM who have financial ties to the pharmaceutical industry" (4). This aspect identified by Cohen speaks to the institutional corruption of the industry central to the problematization of psychiatry in Chapter 2. The productive and financial concerns articulated throughout Marxist and Gramscian discourse are highly applicable to psychiatry.

Marxist understandings of mental health examine psychiatry as a political economic institution and practice: "A Marxist approach to understanding the mental health system necessarily has to analyse professional organisation, discourse, and practice, at both the economic and ideological levels" (Cohen 2016, 34). Quoting Parker (2014), Cohen writes that Marxists are also concerned with psychiatry "as an apparatus that not only participates in the production of value but also ... [becomes] more important to the production, circulation and management, in both the State and civil society, of subjectivity" [emphasis added] (34). The extension of these concerns is articulated through an application of historicism along state, societal, and material lines to the commodification of mental distress:

Scull (1993) argues that the emergence of the psychiatric profession can be explained as a result of the changes in the social organisation of deviance brought about by new market relations. He asserts that the rise of industrial society required a more complex response to social deviance; there was especially a need to adequately control such groups - who were no longer tied to the land, but instead "free" to sell 
their labour to the emerging bourgeois - and separate the non-able bodied (e.g., the sick, disabled, poor, alcoholic, vagrant, and elderly) from the "healthy" population. Thus, the growth of the asylums for "the mad" is understood as an economically efficient means by which groups of deviants could be physically separated from the rest of society and kept under close surveillance by new professional authorities (Cohen 2016, 34).

The commodification of mental distress is a function of the emergence of capitalism and has been present since its origins and maintains class stratification and the furthering of the productive interests of the bourgeoisie. Cohen notes that medical historians have identified a "trade in lunacy" (Scrull 1989, 1993, 2015 in Cohen 2016, 5) that "can be traced to the beginnings of industrial society and witnessed throughout the development of modern mental health work" (Cohen 2016, 5). Over the years mental health has been recommodified in the forms of asylums, institutions, hospitals, and clinics, with pharmaceuticals being its most recent commodified form (Cohen 2016). These institutional arrangements are the same ones that are isolated by Foucauldian scholarship on the matters of madness and psychiatry.

The continuing treatment of mental health concerns as a commodity up to the present day has coalesced into a hegemonic force. Psychiatric hegemony generates induced consent of psychiatric practice through the domination of ideas and discourses reflective of the interests of the dominant social class in shaping and maintaining rule over society (71), reflective of Foucault's arguments about the knowledge/power relationship. Cohen explains the market and financial logics driving modern psychiatry in knowledge production through command of the public narrative:

The more behaviour and experience that can be successfully medicalised - that is, reconceptualised as in need of medical intervention - through this medico-industrial partnership, the more 
drugs can be potentially sold to the public. Thus, it is argued that the expansion of the mental illness discourse is the result of a market takeover of health care; corporations rather than medical practitioners are now designating what mental pathology is and, as a result, dictating treatment. (4)

Psychiatry serves as a powerful tool of production and industrial interest. Therefore, psychiatric hegemony is the manner by which psychiatry persists as a social, political, and economic force. The APA produces the commodity of illness and then treats those illness through the commodities supplied by the pharmaceutical industry. They create disease and cure all while dominating social and policy discourse on mental health, enjoying political privilege and ever-increasing returns on investment while maintaining the interests of the corporate organizations financing the apparatus.

\subsection{Hegemony, Neoliberalism and The Apparatus}

The idea of psychiatry as an apparatus of power is fundamental to Cohen's psychiatric hegemony. Cohen is heavily indebted to Foucault in his conception of psychiatric hegemony, writing of the emergence of ideological state apparatuses (ISAs), institutions that impose capitalist ideology on the working classes, in order to generate popular consent (73). Foucault introduces the idea of the dispositif to his theories of governmentality, which is often translated into English as apparatus. In Foucault's philosophy, apparatus refers to:

.... a thoroughly heterogeneous ensemble consisting of discourses, institutions, architectural forms, regulatory decisions, laws, administrative measures, scientific statements, philosophical, moral and philanthropic propositions-in short, the said as much as the unsaid. Such are the elements of the apparatus. The apparatus itself is the system of relations that can be established between these elements." (Foucault and Gordon 1980, 128). 
Further, the apparatus serves to preserve and extend the possession and exercise of power in and onto society. Frost (2019) explains that the apparatus "represents the network of power relations which articulates how a power not based upon classical conceptions of sovereignty manifests itself. It is through the dispositive [apparatus] that the human being is transformed into both a subject, and an object, of power relations" (152). It is this creation of subjects that is essential to the apparatus, "the term 'apparatus' designates that in which, and through which, one realizes a pure activity of governance devoid of any foundation in being. This is the reason why apparatuses must always imply a process of subjectification, that is to say, they must produce their subject (Agamben 2009, 11). In other words, apparatuses are based upon the articulation of power over something. That something is reducible at its core to individuals that are created by the formulation of the apparatus itself. In the case of the state/psychiatry apparatus, the subjects that are created are the 'mentally ill.' Without the power exerted by modern psychiatry to create discourses, categories, and practices, those subjects would not exist.

Agamben (2009) develops and articulates this idea further, writing "we have then two great classes: living beings (or substances) and apparatuses...[a]nd between these two as a third class, subjects...I call a subject that which results from the relation and so to speak from the relentless fight between living beings and apparatuses" (14). Further, "the same individual, the same substance can be the place of multiple processes of subjectification" (14). Think of the ways that the living being is modeled into subjects by apparatuses: citizen, taxpayer, employee, employer, owner, renter, user, husband, wife, 
son, daughter, student, teacher, soldier, prisoner, patient, madman. One's existence is continuously subordinated to a series of apparatus-directed subject- identities.

The legitimation of psychiatric authority and power is an essential component of the state/psychiatry apparatus. Behind the veil of law, process, and procedure, the abuses of the body and mind inflicted through psychiatric coercion are granted legitimacy and normalcy. This is performed through the networks of knowledge and power interacting and reinforcing the state/psychiatry apparatus and through the creation of the psychiatric subject, the mentally ill individual, who needs to be subjectified for their own good. Without the presence of a psychiatric illness that needs to be treated for the good of the ill individual, and for society, forced confinement, isolation, drugging, electroshocks, and other psychiatric practices would not and could not be acceptable in a democratic, constitutional state, and to many within and outside the apparatus, illness is no justification at all.

As Agamben (2009) writes, "every apparatus implies a process of subjectification, without which it cannot function as an apparatus of governance, but is rather reduced to a mere exercise of violence"(19)..."[the] apparatus, then, is first of all a machine that produces subjectifications, and only as such is it also a machine of governance" (20). The state/psychiatry apparatus creates subjects of psychiatry under the guise of governance through legislation, regulations, policies, procedures, organizations and associations, which provides a justification for the power of psychiatry over the citizen's body, mind and very life; citizens of countries like Canada or the United States have rights (another apparatus), after all. 
At its base, according to Foucault (1995), biopower is manifested in modern disciplinary societies marking the modern era: "in a disciplinary society, apparatuses aim to create - through a series of practices, discourses, and bodies of knowledge - docile, yet free, bodies that assume their identity and their "freedom" as subjects (Agamben 2009, 19-20). Agamben further writes that the apparatus is not only "prisons, madhouses, [or] the panopticon" but "anything that has in some way the capacity to capture, orient, determine, intercept, model, control or secure the gestures, behaviours, opinions or discourses of living beings...writing, literature, philosophy...[and] language itself (14). It is important to look at psychiatry at its most extreme in institutionalization, coercion, compulsion, and abuse but the apparatus and the power strategy involved are constituted of more subtle elements and more outwardly benign practices through the knowledge/power locus at the heart of the apparatus.

That knowledge/power locus is not monolithic or absolute. Agamben(2009) writes that those subjectified by an apparatus, are in a constant form of daily "hand to hand combat" with the apparatus (17). Beyond the subject-identity of the diagnosed mentally ill person, other subject-identities are created in the instrumentalization of state/psychiatry apparatus: psychiatrist, policy-maker, administrator, case worker, etc. There are also subject identities created through resistance to the knowledge and power channels from within and outside the apparatus: critical psychiatrist, psychiatric survivor, psychiatric rights advocate, etc. Each of these identities are created by resistance to the apparatus and act as disrupters to the dominant discourses and practices that constitute the apparatus and these disrupters seek to generate their own knowledge, discourses and practices to reconfigure the relations of power within the apparatus itself. If the resistance 
becomes sufficiently consolidated and focused, it can aggregate into a form of counterapparatus that can radically reform or destroy the apparatus itself. This thesis is itself a contribution to that resistance, however meager.

Foucault, Cohen and the other scholars, researchers, and psychiatrists who have contributed to the body of critical psychiatry literature all essentially, as Burstow (2015) writes, see "psychiatry as an agent of the state" (102). Lost in many of the critical formulations, although certainly implicit, is that the state furthers psychiatry's interests. And the interests of both can fundamentally be reduced down to power and wealth because that is the only tangible thing produced out of this relationship. Psychiatry benefits by having massive amounts of government and private investment in psychiatric research, clinical practice, and pharmaceuticals. The state maintains its power over the individual body, able to mold it to serve the greater hegemonic, neoliberal governing rationale, all while abdicating those very rationales and their resulting discourses and practices of any responsibility in an individual's psychological distress: Society's fine. The Economy's strong. Government's great. You are the problem. And that is the final word because the power behind the state/psychiatry apparatus says that it is.

Whether the relationship is the product of discursive practice and technologies of rule or a product of the capitalist machine and the subordination of the worker to the bourgeoisie is irrelevant. There is certainly evidence for both, and they are not mutually exclusive. The discontinuity between the governmentality lens and the Marxist lens matters less than the harmony in the points of observation that both approaches prioritize. They both see psychiatry as illegitimate, as unethical, and as a tool to represent and project state and government power over the citizen. 


\subsection{The Parameters of the State/Psychiatry Apparatus}

The state/psychiatry apparatus serves a utility from a general perspective in accordance with the apparatus as a network of power. Broadly, an apparatus has three core parameters:

A. It is a heterogeneous set that includes virtually anything, linguistic and nonlinguistic, under the same heading: discourses, institutions, buildings, laws, police measures, philosophical propositions, and so on. The apparatus itself is the network that is established between these elements.

B. The apparatus always has a concrete strategic function and is always located in a power relation.

C. As such, it appears at the intersection of power relations and relations of knowledge. (Agamben 2009, 2-3)

We will term those as the existential parameters. Common to all apparatuses, the existential parameters are what defines the existence of an apparatus. Each apparatus has specific parameters that are particular to its own composition and mode of operation in assuring its power. We shall call those the functional parameters that follow from the existential parameters but are particular to the constitution of each apparatus in and of themselves. Before proceeding with the functional parameters of the state/psychiatry apparatus, Agamben's existential parameters of the apparatus will be supplemented with one addition: legitimation: The aggregation of knowledge and power in the apparatus is legitimated through political means (state and government sanction) and societal acceptance (hegemony). With the existential parameters established, it is possible to examine the functional parameters of the state/psychiatry apparatus.

The term functional parameter is invoked in two senses. First, in the sense that these parameters aggregate to allow the state/psychiatry apparatus to function as an 
apparatus of power in the first place; second, in the sense that these parameters guide its instrumental functions. The functional parameters of the state/psychiatry apparatus are as follows:

1. The state/psychiatry network encompasses the state, governments, regulatory bodies, professional and industry associations, academic institutions, physicians, social workers, police and security agencies, media, and all of the discourses and practices shared in the furtherance of the biomedical model of mental distress. These noted components of the network are by no means exhaustive but serve to encapsulate the major players.

2. The state/psychiatry strategy is to ensure the hegemonic position of psychiatric knowledge and individualized understandings of mental distress within the context of an overarching neoliberal, capitalist order.

3. The state/psychiatry knowledge monopoly involves the prioritization of psychiatric knowledge as the only valid knowledge concerning psychological suffering in human beings.

4. State/psychiatry legitimacy is achieved through the granting of legal and statutory standing to psychiatry as the only legally recognized model of mental health diagnosis and management, while prioritizing that knowledge over the rights of the individual.

The state/psychiatry apparatus operates within these parameters as it encounters individuals. Human beings are surrendered to a process of subjectification where the (bio)power of state legitimizes and instrumentalizes the knowledge claims of psychiatry against its citizens. The following section shall provide context and will help to explain 
the state/psychiatry apparatus by applying the model to Canada and its province of Ontario. 


\section{Chapter 4: The Constitution and Function of the State/Psychiatry}

\section{Apparatus in Ontario, Canada}

The state/psychiatry apparatus was developed, in theory, in Chapter 3. The core functions, composition and parameters were defined along the relations of knowledge, power, and subjectification. This chapter seeks to apply that theory to the province of Ontario and tangentially, the Canadian state and government. Ontario represents a neoliberal polity with a mental health care system dominated by psychiatric knowledge Tobin Leblanc Haley (2017), in a review of the political economy of Ontario's mental health system, found that under neoliberal trends in Ontario's governance "the services that support the daily lives of people with mental illness labels are informed by the imperative of accumulation; the transformation of these services involves three distinct but interrelated trends" (2). These trends are as follows:

1) the application of the neoliberal principles of downloading, privatization, and individualization to existing services, resulting in the on-going placement of many of these services in the non-profit sector; 2) the structuring of mental health care services to condition independence in the activities of daily maintenance and, whenever possible, labour force attachment; and 3) the development in policy and practice of new definitions of mental illness, wellness, and recovery that promote and encourage this economic independence, producing a model of the ideal mental patient as one who is incurably sick, but able to take control of their lives and achieve independence. I refer to this figure of the ideal neoliberal mental patient as the consumer-patient subject. (2-3)

The state/psychiatry apparatus is an instrument of these trends. Presenting the apparatus as a layered network to provide a conceptual model for the operation of the 
state/psychiatry apparatus, this chapter maps the key roles played the component parts of the apparatus's network.

\subsection{The State/Psychiatry Network}

The state/psychiatry network in Canada and Ontario is rather vast and complex. Canada, although not to the degree of other western constitutional democracies, is a neoliberal capitalist state. Its values are in line with the core values of both neoliberalism and capitalism: free markets and trade at a global level, individual liberty, and meritocracy (Teghtsoonian 2009). Canada's system of government involves the constitutional division of powers between the federal government and the provinces, which directs the particular composition of Canada and Ontario's state/psychiatry network (Figure 1). Among the powers that are afforded to the provinces is the organization and provision of healthcare, including mental health. It is a vast and complex network with many different components. It is useful to picture the state/psychiatry network as a layered network, with each layer serving to receive and process power from the apparatus via the state and transmit it to subsequent layers, while transmitting knowledge back up to the apparatus until it is processed consolidated with power to be re-disseminated in a continuous, reinforcing loop.

The federal government, at the executive layer of the state/psychiatry apparatus provides jurisdictional powers and funding to each province, as enabled by the Canada Health Act (1985a). Funding is allocated through the Canada Health Transfer (Department of Finance 2011). The Canadian parliament is one element in the 
governmental layer of the apparatus, alongside the provinces and territories in creating and overseeing the regulatory layer.

The government of Canada determines what funding is delivered to each province and territory through the Canada Health Transfer what types of care are covered by the funding, in line with the Canada Health Act. The government of Canada facilitates the regulatory layer through the passing of laws, regulations, and guidelines, a role that is shared with the provinces and through court precedent. Beyond these funding considerations, the federal government, through Health Canada and the Canadian Institutes of Health Research, provides grants for research and public health programs, performs research in fields of public health policy and health sciences, regulates pharmaceuticals and other medical devices and treatments, and collects public health data, as an active partner in the knowledge layer of the state/psychiatry apparatus. Despite all these functions, the federal government has very little direct role in the practical layer, corrective layer, coercive layer, or subjectification layer of the state/psychiatry network with few exceptions, such as the federal government's responsibility for primary care delivery to members of the Canadian Armed Forces and some veterans (National Defence Act 1985c).

The federal government has very little direct involvement in the governance, organization, regulation, or administration of primary health care to individual Canadians, which is the jurisdiction of Canadian provinces and territories. 
Figure 1: The State/Psychiatry Network

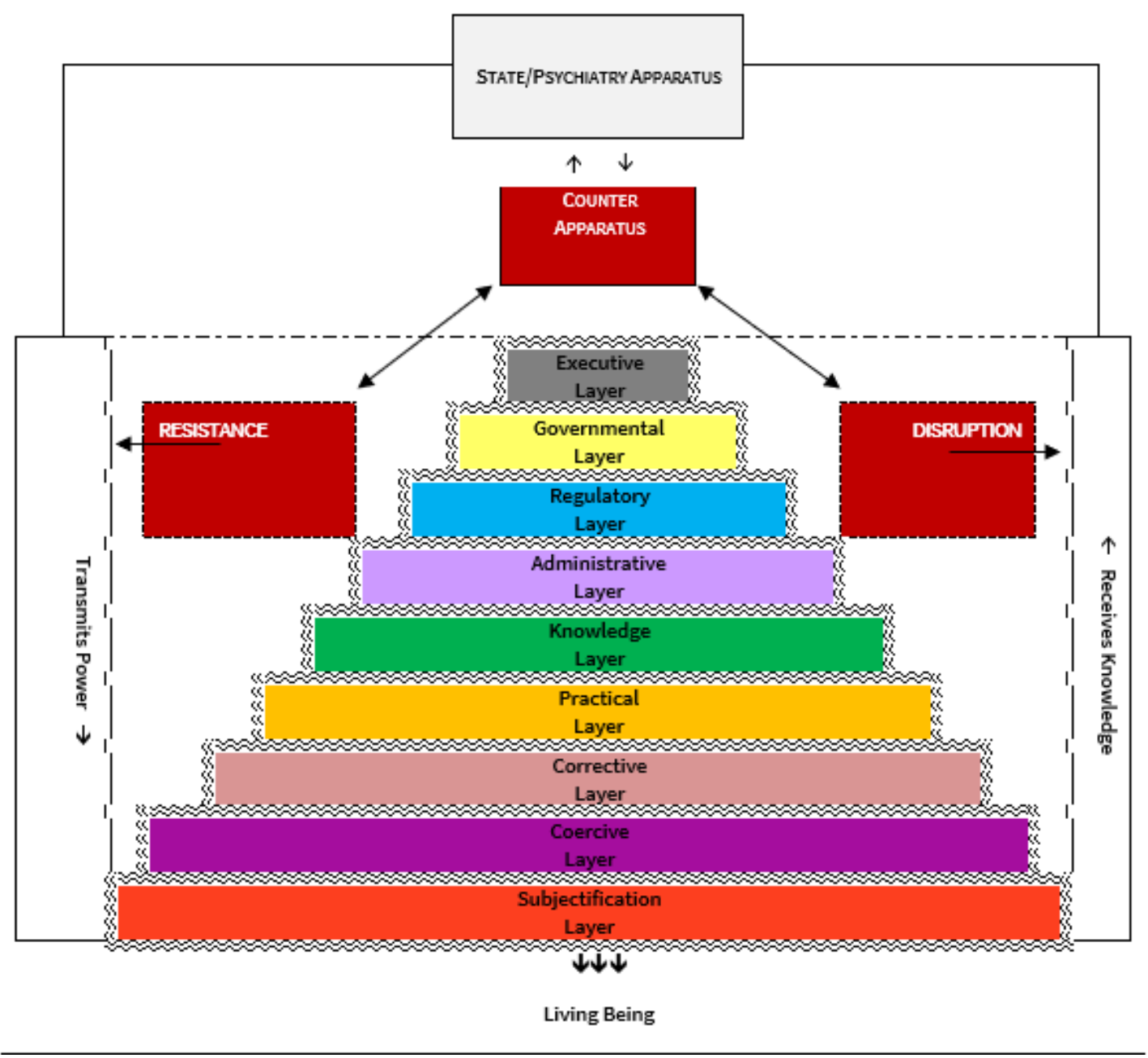

This is a simplified diagram representing the state/psychiatry network as a layered network. Each layer in the network serves a purpose within the functional parameters of the state/psychiatry apparatus and they are all integrated with each other. The executive layer transmits state power while receiving knowledge from the network. This knowledge gets reconsolidated into the power of the apparatus and transmitted back through the network. The apparatus works upon the living being in a process of psychiatric subjectification. Concurrent to the apparatus's function are the discourses and practices that emerge in resistance to the power of the apparatus, disrupting knowledge production and emanating from within and outside the network layers, forming the foundations for the emergence of a counter-apparatus.

Ontario is Canada's most populous province with its biggest provincial economy, and its health system is the largest in Canada. The state/psychiatry apparatus is 
empowered by the Canadian government and state though governed by the province of Ontario for its residents. The state/psychiatry network begins with the power of the Canadian state as wielded by the government of Canada which is then then filtered to the province of Ontario. The Ontario government is directly involved in all layers of the state/psychiatry network, except the executive layer.

Fulfilling its network function at the governmental layer the Ontario government writes and passes legislation into force on matters of health care delivery, funding, regulation, practice, organization, and administration, which compose the regulatory layer of the state/psychiatry network. The influence of psychiatry is made manifest through Ontario's legislation and regulation. Psychiatrists are granted powers of detention and the DSM is legitimized as the diagnostic authority concerning the psychological distress of Ontarians. The administrative layer consists of ministries, agencies, and departments that serve to manage and oversee the implementation and organization of the application of regulations. At the federal level, there is Health Canada and its sub-departments and agencies that have an indirect administrative role in Ontario's mental health system. At the provincial level, there is the Ministry of Health and Long-Term Care and its sub-departments and agencies (Local Health Integration Networks, Regional Public Health Agencies). Additionally, ministries and departments outside of the healthcare portfolio also serve the state/psychiatry apparatus by directing those Ontarians under their charge to psychiatric treatment, often in a coerced manner: Corrections Ontario, The Ontario Parole Board, Ministry of Children and Youth Services, Ministry of Education, School Boards, Department of Child and Family Services, and the Workers Safety and Insurance Board, among others. Each of these departments can to 
some degree or another, coerce Ontarians to be subjected to psychiatric assesments and treatments.

Policy directions concerning mental health are based upon the premise of evidence-based policy making (Health Canada 2010; Public Health Ontario 2018). In the case of mental health policy evidence is supplied by the knowledge layer of the state/psychiatry network within the apparatus. Psychiatric knowledge is privileged by governments and legislation at the expense of other modes of understanding mental distress through academic research, medical journals, clinical practice guidelines, public and private research, lobbying efforts, advocacy groups, professional associations, and media. The province creates regulations and empowers administrative organizations and agencies that facilitate the knowledge production and practices of psychiatry.

Psychiatrists, doctors, nurses, social workers, psychiatric hospitals, community and private treatment clinics, and peer groups constitute the practical layer, where the actual practice of psychiatry takes place. Psychiatric hospitals represent the convergence of many practical components and interactions between other layers in one location, serving as a working micro model of the state/psychiatry apparatus.

Ontario has many psychiatric hospitals legitimated by the governmental layer and the regulatory layer: 80 under the Mental Health Act of Ontario (Ministry of Health and Long-Term Care 2019a), alongside 10 forensic psychiatry facilities under The Criminal Code of Canada, and one facility designated under the Youth Criminal Justice Act of Canada (Ministry of Health and Long-Term Care 2019b). They are managed by components of the administrative layer through the Ministry of Health and Long-Term Care and Local Health Integration Networks (Ministry of Health and Long-Term Care 
2017). Patients of psychiatric facilities interact with the practical layer through the psychiatric hospitals themselves and its various agents: psychiatrists, psychologists, doctors, nurses, social workers, police, etc. The practices are guided by the DSM, clinical practice guidelines, and other elements of the knowledge layer.

The corrective layer of the state/psychiatry apparatus consists of the biomedical interventions themselves, ECT and drug treatment, and on occasion, psychotherapy (Ontario Psychiatric Association 2019). The coercive layer is where psychiatric power over the body is most manifest. It is at this layer that Ontarians can be compelled into treatment and drugging through involuntary treatment via detention in those hospitals or through community treatment orders, which are backed by the Consent and Capacity Board of Ontario, the tribunal that adjudicates when a psychiatric subject disputes their compelled status. Provincial courts also render decisions compelling Ontarians into treatment. The police also have a role in the coercive layer, with the power to detain Ontarians with the sole purpose of bringing them to a psychiatric assessment. And the psychiatric assessment is the moment that the living being becomes the psychiatric subject, the mentally ill person, at the subjectification layer. Even if the relations between psychiatrist and patient is voluntary and the patient finds it productive, the shadow of coercion is always there to dim that light. The layered model of the state/psychiatry network is again used in more detailed form in Figure 2, identifying the various components of the network layers in Ontario. 


\subsection{The State/Psychiatry Strategy}

The state/psychiatry strategy in Canada and Ontario is not unique to their domestic political economies. It is part of the overarching strategic function of the apparatus to ensure the hegemonic position of psychiatric knowledge and individualized understandings of mental distress within the context of an overarching neoliberal, capitalist order (Teghtsoonian 2009; Cohen 2016). This strategy is achieved through the operationalization of knowledge and the legitimation and prioritization of that knowledge which perpetuates the idea of psychological distress as a biomedical issue internal to the living being itself. This empowerment in turn enriches industrial psychiatry through government funding, insurance regimes, pharmaceutical sales, and diagnostic creep. This is evident when looking at Ontario's publicly funded healthcare system.

General practitioners are empowered to prescribe psychiatric medications and the Ontario Hospital Insurance Plan covers only biomedical interventions by medical doctors; therefore only psychiatric care is covered by public health insurance (Government of Ontario 2020b).

In Ontario, there are ways to access alternative forms of psychological services through various publicly funded national, provincial, and community programs delivering counseling and cognitive behavioural therapy in person, over the telephone, or online (Government of Ontario 2020a). Ontario announced its intentions to fund cognitive behavioural therapy and other psychotherapeutic services through its Mindability initiative (Government of Ontario 2020b). However, Mindability only pays for therapy for limited conditions, depression and anxiety, and, along with other publicly funded community mental health programs, they are not universal or permanent in the same way 
that psychiatric treatment is guaranteed as a right through the Canada Health Act or the Ontario Hospital Insurance Plan. Only medicalized, psychiatric care is part of the universal public health insurance system.

Figure 2: The State/Psychiatry Apparatus in Canada and Ontario

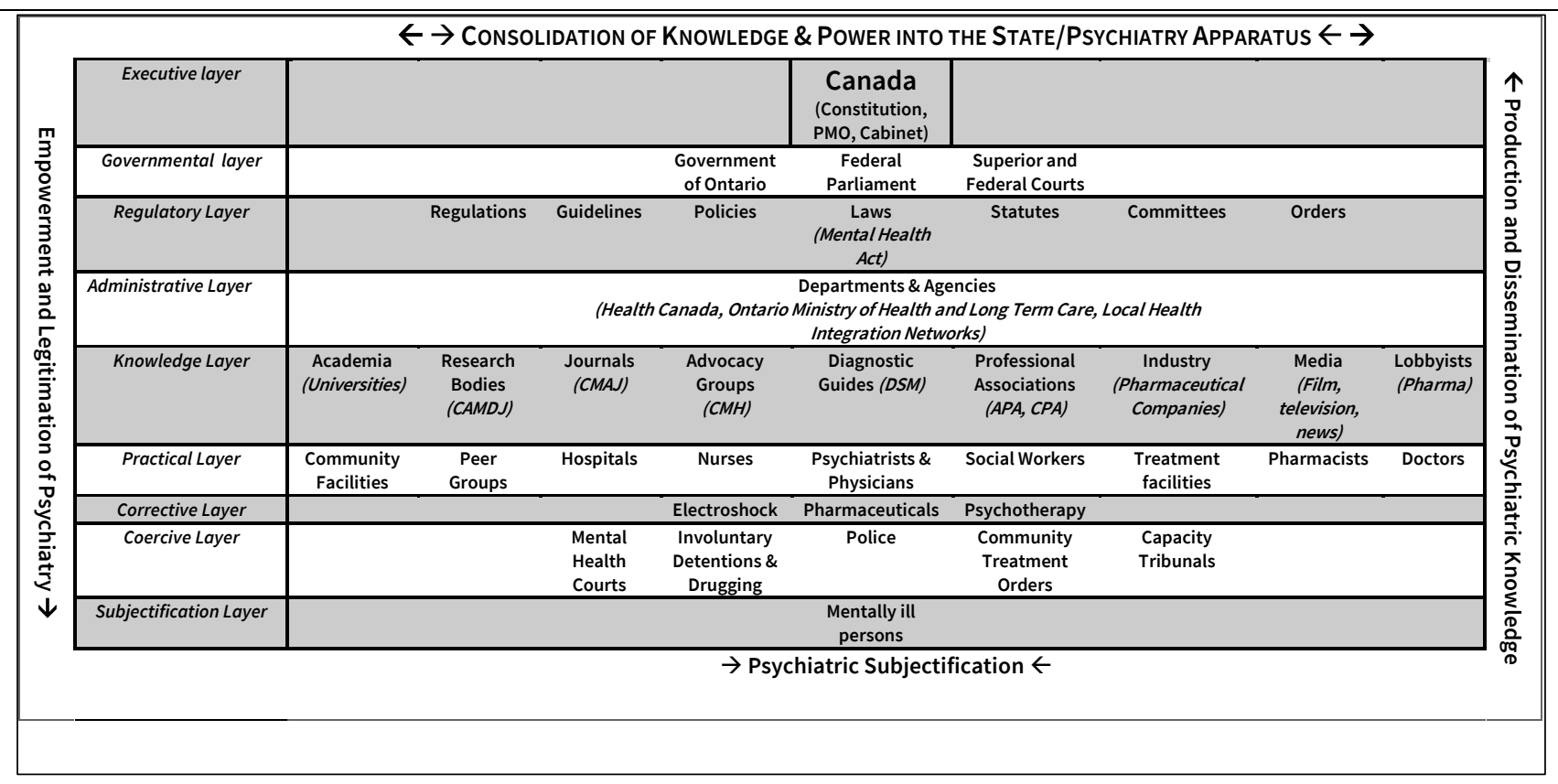

This is a detailed representation of the state/psychiatry network in Canada and Ontario and its functions within the state/psychiatry apparatus. Presented once again in a layered network architecture, each layer has a functionary utility in the maintenance and domination of psychiatric knowledge and practice. Despite a loose hierarchy implicit in the political economic realities of the state system, each node and component in the network is involved in the power dynamics and in the knowledge production of the state/psychiatry apparatus. The layers do not serve as barriers in any way, and each layer can interact with any other layer, independent of, or in combination with any other layer. The constituent components serve to instrumentalize and operationalize state/psychiatric power and knowledge over the living being in the process of psychiatric subjectification.

The Ontario Mental Health Act (1990b) completely disregards alternatives to psychiatry, neglecting to even mention psychologists or therapists. For the vast majority of Ontarians, the only way to have in-person, regular psychological care is if they have private or employer provided insurance or have the financial resources to pay out of 
pocket (Pelley 2016). In other words, psychiatry is privileged to be a right of care, while alternative forms of psychological care are a privilege of economics. Unemployed, uninsured, and economically disadvantaged Ontarians are left with little choice outside of psychiatry in seeking psychological assistance, ensuring psychiatry's continued capture of subjects.

The strategic operation is carried out through the formation and activities of various industry associations and guilds (Table 1) and their presence in academia, research, media, and other institutions. These associations work to disseminate psychiatric knowledge to policy makers and the public to dominate narratives surrounding mental health, thereby manufacturing political and social consent to psychiatric power and practices through legislation, regulation, and public opinion. In Ontario, the state/psychiatric strategy is to enhance psychiatric power and knowledge concerning mental illness, to normalize and foster the acceptance of the idea of mental illness and its treatments through public relations campaigns. These actions serve to normalize compliance to the neoliberal interests of state and society, while abnormalizing, correcting, coercing, compelling, disciplining, and punishing alternative modes of being.

\subsection{The State/Psychiatry Knowledge Monopoly}

The state/psychiatry knowledge monopoly involves the prioritization of psychiatric knowledge as the only valid knowledge concerning psychological suffering in human beings. Knowledge is both created and then disseminated in line with strategic goals concerning psychiatric hegemony. The knowledge monopoly is achieved through the 
coordination of many institutions: industry associations, the DSM, clinical practice guidelines, academic and professional research and journals, and media, among other sources.

The psychiatric system in Ontario is heavily influenced by the APA and the DSM, through multiple channels. The DSM is empowered by various pieces of legislation, either directly by name or implied as the diagnostic authority on mental disorders and mental illness; both terms are used in legislation.

The Canadian Psychiatric Association publishes Clinical Practice Guidelines (Canadian Psychiatric Association n.d.), alongside the Canadian Network for Mood and Anxiety Treatments (CANMAT) (Canadian Network for Mood and Anxiety Treatments n.d.). In addition to the Canadian Psychiatric Association, there are a host of other psychiatric guilds and associations that are organized by specialized interest or territory. The American Psychiatric Association operates in Canada, with three regional offices: Western Canada, Ontario, and Quebec and Eastern Canada (American Psychiatric Association 2020).

In conjunction with industry associations are publicly funded research bodies and advocacy organizations that contribute to the curation and dissemination of psychiatric knowledge. Table 1 provides a partial list of the various associations that contribute to the generation, maintenance, and monopolization of psychiatric knowledge and practice while pursuing the strategic growth of industrial psychiatry. Each of these associations has a role in representing the interests of biomedical psychiatry to society which in turn has had a net increase on the influence and wealth of industrial psychiatry to varying degrees. 
Table 1: Professional and Guild Associations

\begin{tabular}{|c|c|c|}
\hline ASSOCIATION & SPECIALIZED INTEREST & TERRITORY \\
\hline $\begin{array}{l}\text { AMERICAN ASSOCIATION OF CHAIRS OF } \\
\text { DEPARTMENTS OF PSYCHIATRY (AACDP) }\end{array}$ & $\begin{array}{l}\text { Academic delivery and pedagogy of psychiatric } \\
\text { education representing all medical schools in the } \\
\text { USA and Canada (American Association of Chairs of } \\
\text { Departments of Psychiatry 2020) }\end{array}$ & Canada, USA \\
\hline $\begin{array}{l}\text { AMERICAN PSYCHIATRIC ASSOCIATION } \\
\text { (APA) }\end{array}$ & $\begin{array}{l}\text { Professional development of psychiatric } \\
\text { knowledge and practice (American Psychiatric } \\
\text { Association 2020) }\end{array}$ & Canada, USA \\
\hline $\begin{array}{l}\text { CANADIAN ACADEMY OF GERIATRIC } \\
\text { PSYCHIATRY (CAGP) }\end{array}$ & $\begin{array}{l}\text { Clinical practice and education in geriatric } \\
\text { psychiatry (Canadian Academy of Geriatric } \\
\text { Psychiatry 2020) }\end{array}$ & Canada \\
\hline $\begin{array}{l}\text { CANADIAN ACADEMY OF PSYCHIATRY AND } \\
\text { THE LAW (CAPL) }\end{array}$ & $\begin{array}{l}\text { Forensic psychiatry (Canadian Academy of } \\
\text { Psychiatry and the Law 2020) }\end{array}$ & Canada \\
\hline $\begin{array}{l}\text { CANADIAN ACADEMY OF PSYCHOSOMATIC } \\
\text { MEDICINE }\end{array}$ & $\begin{array}{l}\text { Clinical, educational, and research in } \\
\text { psychopharmaceuticals }\end{array}$ & Canada \\
\hline $\begin{array}{l}\text { CANADIAN ASSOCIATION OF CHILD AND } \\
\text { ADOLESCENT PSYCHIATRY }\end{array}$ & Clinical practice in adolescent and youth psychiatry & Canada \\
\hline $\begin{array}{l}\text { CANADIAN MENTAL HEALTH ASSOCIATION } \\
\text { (CMHA) }\end{array}$ & $\begin{array}{l}\text { Public mental health services, research, education, } \\
\text { and advocacy }\end{array}$ & Canada \\
\hline $\begin{array}{l}\text { CANADIAN INSTITUTES OF HEALTH } \\
\text { RESEARCH (CIHR) }\end{array}$ & Neoruopsychiatric research & Canada \\
\hline CANADIAN MEDICAL ASSOCIATION (CMA) & $\begin{array}{l}\text { Professional development, medical research, } \\
\text { education, clinical care and delivery, policy } \\
\text { advocacy (Canadian Medical Association 2020) }\end{array}$ & Canada \\
\hline $\begin{array}{l}\text { CANADIAN MEDICAL PROTECTIVE } \\
\text { ASSOCIATION (CMPA) }\end{array}$ & $\begin{array}{l}\text { Liability, legal assistance, and malpractice } \\
\text { insurance (Canadian Medical Protective Association } \\
\text { n.d.) }\end{array}$ & Canada \\
\hline $\begin{array}{l}\text { CANADIAN NETWORK FOR MOOD AND } \\
\text { ANXIETY DISORDERS (CANMAT) }\end{array}$ & $\begin{array}{l}\text { Clinical practice guidelines, research and education } \\
\text { for mood disorders (Canadian Network for Mood } \\
\text { and Anxiety Treatments n.d.) }\end{array}$ & Canada \\
\hline $\begin{array}{l}\text { CANADIAN PSYCHIATRIC ASSOCIATION } \\
\text { (CPA) }\end{array}$ & $\begin{array}{l}\text { Professional development of psychiatric } \\
\text { knowledge and practice (Canadian Psychiatric } \\
\text { Association n.d.) }\end{array}$ & Canada \\
\hline $\begin{array}{l}\text { COLLEGE OF PHYSICIANS AND SURGEONS } \\
\text { OF ONTARIO (CPSO) }\end{array}$ & $\begin{array}{l}\text { Accreditation of medical professions, including } \\
\text { psychiatry, ethics complaints and disciplinary } \\
\text { actions (College of Physicians and Surgeons of } \\
\text { Ontario 2020) }\end{array}$ & Ontario \\
\hline ONTARIO PSYCHIATRIC ASSOCIATION (OPA) & $\begin{array}{l}\text { Professional development of psychiatric } \\
\text { knowledge and practice (Ontario Psychiatric } \\
\text { Association 2019) }\end{array}$ & Ontario \\
\hline $\begin{array}{l}\text { A partial list of players in the gener } \\
\text { monopolization in the Ontario state } \\
\text { organizations professionalize psych } \\
\text { industrial society, in partnership wi }\end{array}$ & tion of psychiatric knowledge and its & $\begin{array}{l}\text { lds and } \\
\text { rests of }\end{array}$ \\
\hline
\end{tabular}

While the DSM provides the categorical definitions, symptoms and diagnostic pathways for mental illness and psychiatric disorders, clinical practice guidelines provide psychiatrists and adjacent practitioners (general practitioners, nurses, social workers, etc.) with guidance on how to effectively manage disorders found in the DSM. These 
guidelines are developed as a professional reference for clinical psychiatrists concerning medications, dosages, and other treatment practices. Their authorship is in the hands of private industry associations that work in coordination with the APA and industrial psychiatry. They are premised upon the biomedical model and are highly concerned with medication management above all else.

In Canada, there is not a single source for clinical practice guidelines, but a hodgepodge of domestic, American, and international resources for clinical psychiatric practice. While international guidelines are certainly more prevalent, detailed, and up-todate than domestic guidelines, within Canada, guidelines are periodically produced by the CPA and the CANMAT. These guidelines can often be linked back to both the APA and the pharmaceutical industry and the problems associated with them (Whitaker and Cosgrove 2015). For example, in the case of the most recent CANMAT CPG for bipolar polar disorder (Yatham et al. 2018), it was developed in cooperation with the International Society for Bipolar Disorders, which was founded in 1998 in Pennsylvania by married psychiatrists Ellen Frank and David Kupfer (International Society for Bipolar Disorders n.d.). Dr Kupfer was the head of the DSM-V taskforce and used his position to advocate a dimensional model of psychiatric assessment and software tools that he was financially invested in (Hickey 2014; Steingard 2014). CANMAT also has partnerships with the International Bipolar Foundation, formerly the California Bipolar Foundation, an advocacy and education organization that forwards a biomedical understanding of bipolar disorder as a "brain disease" (International Bipolar Foundation 2013). Canadian CPGs are hardly Canadian at all, but merely conduits for the APA and the DSM. 
Canada and Ontario both fund public universities. Among the funded institutions are medical schools with departments of psychiatry (Table 2). These schools provide specialized psychiatric education to medical school graduates in the fields of clinical practice, theories of the mind, research methods, and psychopharmacology.

Unsurprisingly, the influence of the APA on Canadian psychiatric education can be found beyond just the DSM and American published texts and CPGs, but also through the chairs of psychiatric departments in Ontario and Canada. Every psychiatric departmental chair of Ontario and Canadian medical schools is also a member of the American Association of Chairs of Departments of Psychiatry (AACDP) (American Association of Chairs of Departments of Psychiatry 2020), which is an affiliate partner and participant in the APA (Soundy 2020).

Ontario medical schools have clinical and research partnerships with Ontario's psychiatric hospitals, which also factor into knowledge generation. These relationships between clinical centres and academia are key in the development, consolidation, and monopolization of psychiatric knowledge. A striking example of this arrangement and its effects can be observed through The Centre for Addiction and Mental Health (CAMH) in Toronto.

Table 2: Ontario Medical Schools

\begin{tabular}{l|l}
\hline \multicolumn{1}{c|}{ UNIVERSITY } & \multicolumn{1}{c}{ LOCATION } \\
\hline McMaster University Michael G. DeGroote & Hamilton, Waterloo, St. Catharines \\
School of Medicine & Sudbury, Thunder Bay \\
Northern Ontario School of Medicine & Ottawa \\
University of Ottawa & Kingston \\
Queen's University & Toronto \\
University of Toronto & London \\
Schulic School of Medicine and Dentistry & \\
(University of Western Ontario) & \multicolumn{1}{|c}{ (“Ontario Medical Schools (OMSAS)” n.d.). } \\
\hline A list of medical schools in Ontario (OM
\end{tabular}


The CAMH has been the subject of scandals and a precedent-setting Supreme Court of Canada decision in R. v. Conway, which ruled that in the case of a forensic patient who had been involuntary at CAMH for 27 years, the Ontario Review Board (now the Consent and Capacity Board) had the obligation to consider and apply the Charter of Rights of Rights and Freedoms as a "court of competent jurisdiction" to its decisions regarding the mental capacity and consent to treatment of Mr. Conway (Bredt and Krajewska 2011).

The CAMH website does an excellent job of summarizing the relationship between knowledge, economics, power, politics, and practice in a statement that represents the network layers, and their relations in strategy, knowledge generation, and legitimation that form the functional parameters of the state/psychiatry apparatus:

CAMH is fully affiliated with the University of Toronto and is a Pan American Health Organization/World Health Organization Collaborating Centre. With a dedicated staff of more than 3,000 physicians, clinicians, researchers, educators and support staff, CAMH offers outstanding clinical care to more than 34,000 patients each year. The organization conducts groundbreaking research, provides expert training to health care professionals and scientists, develops innovative health promotion and prevention strategies, and advocates on public policy issues at all levels of government. And through our Foundation, we're working to raise tens of millions of additional dollars to fund new programs and research and augment services (Centre for Addiction and Mental Health 2020).

The totality of the state/psychiatry apparatus is packed into one paragraph. Canada and Ontario fulfill combined functions of executive, governmental, and regulatory layers through funding and legislation, with the province creating the agencies of the administrative layer. CAMH is an active participant in network layers encompassing knowledge through its research programmes and affiliations with the 
University of Toronto while linked to the neoliberal hegemonic apparatus in partnering with the Pan American and World Health Organizations. Its role in the practical, corrective, coercive, and subjective layers is part of its primary clinical function. This network convergence is all operationalized and directed towards their self-stated financial goals that, if achieved, will be reinvested in the continued maintenance of the state/psychiatry apparatus itself.

Media also plays a role in psychiatric knowledge generation and dissemination by shaping public attitudes towards psychiatry and psychiatric concepts like biomedical mental illness. Beyond the monolithic presence of Hollywood representations of mental illness in films and television, psychiatric knowledge generation has spread to new forms of media.

Figure 3: Advertisement

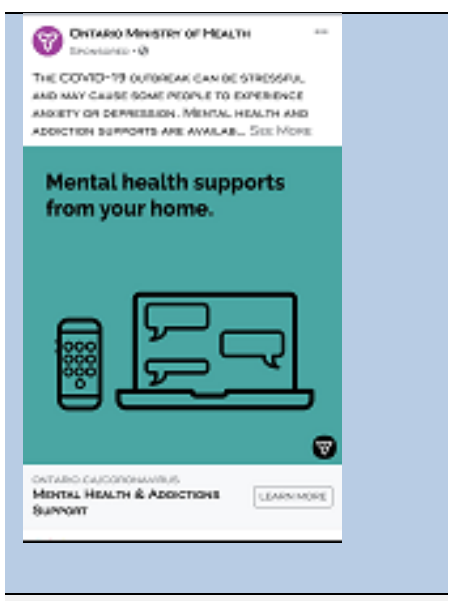

Facebook ad for mental health services being offered by province of Ontario (Ministry of Health and Long-term Care 2020)

The Bell Let's Talk website has a 'Get Help' section that offers information and links to various partners (CAMH, CMHA, Mood Disorders Society of Canada), that all perpetuate a
Canada's largest telecommunications company, Bell, sponsors Bell Let's Talk Day, an annual media and public relations campaign, which seeks to 'end the stigma of mental illness,' to provide education and access to mental health care resources, and provide mental health research funding (Bell Let's Talk 2020b). The campaign has received criticism for being nothing more than a cynical corporate public relations campaign, in league with the corporate and financial interests of psychiatry and pharmaceuticals that ends up "harming the people it aims to help" (Pifer 2019). 
medicalized view of mental health, stressing the validity of mental illness and their comparability to physical illness, and touting the efficacy and importance of psychiatric medication (Bell Let's Talk 2020a).

Social media's algorithmic, personalized, psychometric targeted advertising also represents another channel of public knowledge concerning psychiatry. The province of Ontario is advertising mental health services on Facebook (Figure 3) that are in response to the socio-economic impacts on mental health caused by COVID-19. This platform represents a way for the state/psychiatry apparatus to capture more subjects given the psychometric algorithms that can identify ideal target audiences based on user profiling.

\subsection{State/Psychiatry Legitimacy}

State/psychiatry legitimacy is achieved through the granting of legal and statutory standing to psychiatry as the only legally recognized model of mental health diagnosis and management while prioritizing that knowledge over the rights of the individual. Mental health is a medical phenomenon in Canada in Ontario as defined by the APA and the DSM. At both the federal and provincial level there are a series of acts, legislation, and statutes that empower psychiatry over citizens, legitimates the concept of biomedical mental disorders, privileges the DSM, and enables forced assessment, detention, or treatment (Table 3). The powers of psychiatry over the living body up to and including compulsive practices are exerted primarily through provincial legislation. In Ontario, the Mental Health Act (1990b) in combination with the Health Care Consent Act (1996) enables involuntary treatment, community treatment orders, isolation, mechanical and chemical restraint, forced medication and electroshock, alongside other mechanisms of 
psychiatric compulsion that afford psychiatrists the full detentive powers of the state over the individual. These powers may be invoked if a psychiatrist deems that an individual lacks the capacity for consent and that it is in the "best interest" of the individual. Police are often called to deal with and have the right to detain those in mental distress, without the guarantee of access to a lawyer as with criminal detainees; these mental health interactions often end with tragic results, including the deaths of the distressed (Tsekouras 2020).

Once a psychiatric patient is hospitalized in Ontario, there are a series of bureaucratic and regulatory injunctions that give the hospitalization the appearance of being part of a rational, rights-focused regime that only uses the involuntary powers of the Mental Health Act (1990b) and Health Care Consent Act (1996) in extreme circumstances. Yet, the incidence of involuntary hospitalizations has seen a steady increase (along with the total number of hospitalizations overall) since the turn of the $21^{\text {st }}$ century (Lebenbaum et al. 2018). As a percentage of total psychiatric hospitalizations, involuntary hospitalizations accounted for $25 \%$ nation-wide in the 1970s, while in 2013 , in Ontario, $77.1 \%$ of hospitalizations were involuntary (31).

Further, despite the constitutional and statutory rights codified in law, patients' bills of rights developed by hospitals, and the provision of patients' rights advocates (who work for the institutions that they are to advocate against, often as side by side colleagues with psychiatrists, many of whom form friendships and social relationships), the Ontario psychiatric hospital system has been beset with scandal and accusations of gross human rights violations (Bredt and Krajewska 2011) including the use of solitary confinement, 
administration of psychotropic drugs without consent, assault, and brainwashing that the Ontario Superior Court of Justice ruled was torture (Fine 2017).

There are still active cases before the Ontario Superior Court alleging the same: that patients were systematically tortured by psychiatrists and used as "human guinea pigs" at the psychiatrists' whims on the level of experiments carried out by Nazi Germany (Perkel 2019). Litigating against psychiatrists in civil court is difficult, as the

Table 3: Legitimating Acts and Legislation

\begin{tabular}{|c|c|c|c|c|}
\hline $\begin{array}{l}\text { Act or } \\
\text { Legislation }\end{array}$ & $\begin{array}{c}\text { Empowers } \\
\text { Psychiatry/Psychiatrists }\end{array}$ & $\begin{array}{l}\text { Legitimates Biomedical } \\
\text { Mental Disorder or Illness }\end{array}$ & $\begin{array}{l}\text { Privileges } \\
\text { DSM }\end{array}$ & $\begin{array}{l}\text { Enables Forced } \\
\text { Examination/Detention/Treatment }\end{array}$ \\
\hline \multicolumn{5}{|c|}{ FEDERAL LEGISLATION } \\
\hline $\begin{array}{l}\text { Canada Health } \\
\text { Act (1985) }\end{array}$ & No & Yes ( s. 2) & No & No \\
\hline $\begin{array}{l}\text { Criminal } \\
\text { Code of Canada } \\
(1985)\end{array}$ & Yes (s. 672) & $\begin{array}{l}\text { Yes (ss.2, 16, } 490676,672,675, \\
686,691 \text {, Form 48, Form 49, Form } \\
\text { 50, Form 53) }\end{array}$ & No & Yes (s. 672) \\
\hline $\begin{array}{l}\text { Corrections } \\
\text { and } \\
\text { Conditional } \\
\text { Release Act } \\
(1992)\end{array}$ & Yes (s. 132) & Yes (ss. 85, 132) & No & Yes (s. 88) \\
\hline $\begin{array}{l}\text { Youth Criminal } \\
\text { Justice Act } \\
(2002)\end{array}$ & Yes (s. 34) & Yes (ss. 98,104) & No & Yes $(\mathrm{ss} .98,131)$ \\
\hline $\begin{array}{l}\text { National } \\
\text { Defence Act } \\
(1985 c)\end{array}$ & Yes (s. 202) & Yes (div. 7) & No & Yes (s. 202) \\
\hline $\begin{array}{l}\text { Firearms Act } \\
\text { (1985b) }\end{array}$ & Yes (s. 5) & Yes (s. 5) & No & No \\
\hline $\begin{array}{l}\text { Sex Offender } \\
\text { Information } \\
\text { Registration } \\
\text { Act (2004) }\end{array}$ & No & Yes (ss. 3, 8) & No & No \\
\hline \multicolumn{5}{|c|}{ PROVINCIAL LEGISLATION } \\
\hline $\begin{array}{l}\text { Mental Health } \\
\text { Act (1990b) }\end{array}$ & Yes (ss. 1, PART I-V) & Yes (ss. 1, PART I-V) & No & Yes (PART II) \\
\hline $\begin{array}{l}\text { Health Care } \\
\text { Consent Act } \\
(1996)\end{array}$ & Yes & Yes & No & Yes \\
\hline $\begin{array}{l}\text { Substitute } \\
\text { Decisions Act } \\
\text { (1992) }\end{array}$ & Yes (ss. 1, 15, 20) & No & No & No \\
\hline $\begin{array}{l}\text { Workplace } \\
\text { Safety and } \\
\text { Insurance Act } \\
\text { (1997) }\end{array}$ & Yes (ss. 14) & Yes (ss. 14) & Yes (ss. 14) & No \\
\hline $\begin{array}{l}\text { Education } \\
\text { Act(1990a) }\end{array}$ & Yes (s. 171) & No & No & No \\
\hline
\end{tabular}




\begin{tabular}{|l|l|l|l|l|}
\hline $\begin{array}{l}\text { Provincial } \\
\text { Offences Act } \\
\text { (1990c) }\end{array}$ & Yes (s. 44) & Yes (s.44) & Yes (s. 44) \\
$\begin{array}{l}\text { Occupational } \\
\text { Health and } \\
\text { Safety Act }\end{array}$ & Yes (s. 43) & No & No & \\
\hline $\begin{array}{l}\text { Social Contract } \\
\text { Act (1993) }\end{array}$ & Yes (Appendices) & Yes (Appendices) & No \\
\hline
\end{tabular}

Psychiatric knowledge, epistemology, and ontology are represented and legitimized through a series of federal and provincial acts. This is but a partial list of federal and provincial legislation that acts to empower psychiatry as a concept and psychiatrists as practitioners, legitimize and define biomedical mental illness, privilege the APA and the DSM, and facilitate psychiatric compulsion and coercion. This list was generated by doing textual searches in the acts for the following terms: psychiatry, psychiatrist, psychiatric, psychiatric disorder, DSM, diagnostic and statistical manual, involuntary, involuntary treatment, involuntary hospitalization, mental, mental illness, mental disorder, psychology, psychological, psychological disability. This list is not exhaustive but serves to represent the depth of the legislative representation of psychiatry in Canada and Ontario.

Mental Health Act (1990b) indemnifies psychiatrists and other staff against most tort liability, with the province subrogating the role of defendant in any actions brought by psychiatric victims (s. 79).

In cases where psychiatrists are sued in court and the suits are allowed to proceed, plaintiffs must deal with the Canadian Medical Protective Association (CMPA), which provides liability insurance and offers legal defense for Canadian doctors (Canadian Medical Protective Association n.d.). This association is funded by premiums collected from all practicing doctors in Canada. However, this is misleading as those premiums are often subsidized or reimbursed by provinces. In Ontario, these reimbursements exceed $\$ 100$ million dollars annually, with up to 83 percent in all fees paid by physicians returned (Clarke 2012, n.p.). This creates a situation where when Ontarians do take physicians and psychiatrists to court, they are fighting against defendants who not only have more legal resources and funding but are sponsored by the government. In essence, if somebody takes a doctor to court in Ontario, they are fighting 
not only the physician and the CMPA, but their own government. This represents yet another instance where the state/psychiatry apparatus acts upon the individual in a subjectification process.

Most patients who contest their involuntary hospitalization or community treatment orders have no recourse other than the Consent and Capacity Board of Ontario (CCB). The board serves as an ostensibly independent review board that reviews involuntary admissions upon receipt of a patient application. (Consent and Capacity Board of Ontario 2020). The review will only proceed if the applicant is still detained on the date of the hearing, in common with British Colombia and other Canadian jurisdictions (Paul et al. 2020; Johnston 2017). This set-up creates an environment where, if a psychiatrist wants to avoid appearing before the $\mathrm{CCB}$, they can simply discharge the patient which eliminates the CCB's jurisdiction in the matter, immunizing the psychiatrist from external scrutiny.

At the review tribunal, the fate of the applicant is decided by a three to five member panel consisting of at least a psychiatrist, a lawyer, and a citizen representative (Consent and Capacity Board of Ontario 2020). Despite the appearance of fairness and openness that is fostered by the professional and legal apparatus that supports the CCB, the decisions are arbitrated on procedural adherence by the certifying staff of psychiatrists.

This frame of judgement is prioritized over the rights and values of the individual or the validity of the diagnosis, or treatment harms themselves. As a result $\mathrm{CCB}$ rulings are overwhelmingly in favour of psychiatrists' opinions (Moss and Redelmeier 2010; Lebenbaum et al. 2018). Moss and Redelmeier found in a 2010 study that only 18 percent 
of tribunal decisions were resolved in favour of the applicants (94). While board members, physicians, and psychiatrists overwhelmingly believe that the process is fair, open, and respectful of patient rights and well-being (Lebenbaum et al. 2018), patients and their legal representatives found the $\mathrm{CCB}$ to be biased in favour of psychiatric authority with patients feeling that "board members focused too narrowly on their diagnosis, ignoring them as 'a person' and dismissing their strengths...[t]hey felt that in the process they were perceived as a sick person rather than an individual citizen" while placing "higher value on the psychiatrist's views than theirs" (Lebenbaum et al. 2018, 6). This is ultimate articulation of the state/psychiatry apparatus. The subjectification is complete. Any chance of having some from of redress, apology, autonomy, or restoration of self-identity is crushed under the weight of bureaucratic government and its prioritization of psychiatrists' interests over that of the citizen, the individual, the very living being who has now had their existence and identity completely and totally subjectified without any further recourse available. The transformation from person to mentally ill person is complete, total, and final.

\subsection{The State/Psychiatry Apparatus in Summary}

The state/psychiatry apparatus is strong and vast in Canada and Ontario. It facilitates state and government interest in its economic and political goals by maintaining the neoliberal hegemonic apparatus. The mental health system in Canada is dominated by psychiatry, biomedicine, and individualized understandings of mental distress. Power is diffused by the state through the layers of the state/psychiatry network, allowing the apparatus to fulfill its functional parameters. 
The state/psychiatry strategy is designed and implemented by components of the administrative layer through agencies and departments, the knowledge layer through professional associations, research bodies, academia, journals, and media. The state/psychiatry knowledge monopoly is created by these same components and serves as the fuel to the strategic fire, while state/psychiatry legitimacy is achieved through the empowerment of the practical, corrective and coercive layers (psychiatrists, medication, involuntary treatment, etc.) by legislation, regulations, rights-based narratives and other methods of legitimation innate to governmentality, capitalism and neoliberal, economic government. All the while, in the case of Ontario, Canada, and globally, knowledge and power coalesce into the apparatus, capturing living beings in the subjectification layer, creating the psychiatric subject "the mentally ill person, defined by a psychiatric diagnosis often at the expense of all other subject-identities of the individual, deprived of their rights, and living in the constant shadow of coercion. 


\section{Chapter 5: Conclusion}

The relevance of the issue at hand has taken on a more urgent dimension in the wake of the COVID-19 pandemic. In the midst of an already-growing national and global burden of mental illness at crisis proportions, the isolation and economic calamity resulting from the pandemic is expected to intensify the rate of psychological distress among Canadians, placing greater demands on an already strained mental health system (CMHA 2020). And that system, as constructed, is dominated by psychiatry.

The goals of this theoretical examination of the political economy of psychiatry are multifaceted. Firstly, by conceptualizing the state/psychiatry apparatus as a political economic phenomenon, it allows us to prevent the isolation of psychiatry from politics, parading as sound medical science. The state/psychiatry apparatus is a political economic institution that is concerned with the exertion of state and governmental power over the living being, creating subjects of the state and of psychiatry. To separate psychiatry from politics and economics is a disservice to the realities of industrial psychiatry and its effects on society. The facts are that psychiatry is an entity with massive amounts of political power over societal attitudes towards psychological distress and the individual body and mind in addition to a massive consumer industry, especially in light of its relationship with pharmaceutical companies.

The history and present of psychiatry are littered with conflicts of interest, financial and ethical corruption, and gross abuses of human rights, all packaged in the guise of evidence-based medical care. The results of these considerations along with the support psychiatry receives from the state over the individual are staggering and often tragic. The United Nations, Ontario Superior Court, a host of critical psychiatry scholars 
and organizations, and psychiatric survivors recognize that many psychiatric practices, especially coercive practices, are torture.

The medical interventions proposed by psychiatry are administered absent any type of evidence for biological causes for mental illnesses that can be objectively tested. Trading on a series of disproven or undeveloped theories, such as the chemical imbalance myth, the biological etiology of psychological distress is nothing than a hope for an industry that it will someday validate its knowledge and practices. A half century on, the biomedical and psychopharmacological approaches to human psychological suffering have only exacerbated the issue with more diseases, more diagnoses and more drugs, yet little in the way of results.

That liberal western democracies premised upon constitutional rights continue to empower psychiatry is telling. Despite the declarations from the Canadian state regarding openness, equality, fairness, and acceptance, the psychiatric subject is often alienated from such ideas. The fact remains that the state/psychiatry apparatus is embedded in the neoliberal hegemonic apparatus at the heart of the global political economy.

The conceptualization of the state/psychiatry apparatus can serve to form a counter-apparatus. As with Cox, Foucault, Marx, Gramsci, Agamben, and the other professionals, scholars, and researchers cited herein, it is hoped that this contribution achieves the goal of articulating truth to power in a way that can focus critical psychiatry movements into a political economic entity in and of itself that interrupts power networks, generates new modes of understanding and knowledge, and is validated and legitimated through political processes of states and governments. 
There is a diverse body of critical psychiatry literature and action groups that are gaining support and momentum. Globally, the United Nations, in The Convention on the Rights of Persons with Disabilities, has been very explicit in its calls to end involuntary treatment and the torturous practices that come with it. There have been national, regional and international networks built through organizations like Mindfreedom International, The Hearing Voices Network, and the Psychiatric Survivors Network that seek to humanize mental suffering. Associations from within psychiatry, such as the Council for Evidence-based Psychiatry and without, like Mad in America, have formed that seek to challenge the psychiatric knowledge monopoly and demand an ethical, rights-centered approach to the treatment of psychological distress that prioritizes social, political, and economic justice and equality.

The bottom line is that psychological suffering is real. It is immediate. It is negatively impactful to individuals, their support networks, and their societies. That suffering, however, cannot for any scientific or evidence-based reason be blamed on biomedical illness. The political economic realities of increasingly unequal societies prioritizing capitalist interests and growth while demanding more and more out of individuals who get less in return have taken their tolls. And until there is a movement to seriously rectify the inherent injustices innate to the neoliberal hegemonic apparatus, the state/psychiatry apparatus will continue to have a role in perpetuating the interests of the neoliberal political economies of states and the global system at large, while blaming the individual for the suffering they endure at its hand.

Yet there is a nascent counter apparatus forming to challenge the authority of the state/psychiatry apparatus. As forms of state and psychiatric power are resisted through 
the work of human rights advocates, critical psychiatrists, academics, scholars, lawyers, and psychiatric survivors and agents within the layers of the state/psychiatry network formulate critical and disruptive knowledge and practices, there is hope that there will come a day when all those suffering from psychological distress will be treated humanely, according to their beliefs and values, based on the best evidence possible, free of the shadow of coercion that leads to the incarceration of desperation.

This thesis represents an exercise in theory-building to answer the question of how and why psychiatry persists as the dominant authority on mental health and psychological suffering despite the inherent problems in its validity, reliability, efficacy, and ethics. The result is highly abstract and broad in nature. But that comes with the territory as psychiatry itself is highly abstract and broad in nature, despite its attempts to appear scientific. There are numerous avenues of exploration that had to be abandoned during the research process due to the constraints of scope and space. The impacts of psychiatry on children, its racial and ethnic biases in practice, political suppression and indoctrination programs on behalf of states, and the role of psychiatry in the military and warfare were all worthy of exploring as elements of the state/psychiatry apparatus and would be excellent focus areas for further research. Additionally, the research into Canada and Ontario was constrained by the lack of readily available statistical data (Mental Health Commission of Canada 2014) from the various layers of psychiatric governance, regulation, and administration institutions. Unlike the United States and other jurisdictions (Mental Health Commission of Canada 2014, 45), data concerning pharmaceutical sales, tribunal decision rates, lobbying expenditures, research transparency was hard to come by and often available through secondary or tertiary 
analysis and reporting. Given more time and resources, through freedom of information regulations, much of this data could possibly be acquired and published.

Additionally, the responses of psychiatry to the critical literature, of which there are many, were omitted. While engaging and responding to psychiatric apologetics is certainly a worthwhile effort, the power and knowledge domination of the industry presented herein speaks for itself. Psychiatry is the dominant discourse on mental health, its epistemology, ontology, methodology, discourses, practices, ideas, values, and ethics are on full display for all to see. This thesis is concerned with interrogating that dominance as it is represented in the political economy and society. Any responses by agents of psychiatry would simply be restating the status quo.

There is certainly room for further improvement and development of the ideas presented herein. It is sincerely hoped that this effort inspires others to pick up the task and continue to illuminate the workings of the power, knowledge, and subjectification of the state/psychiatry apparatus in the political economy of psychiatry. If I have been successful herein, then the theory of the state/psychiatry apparatus will serve as an analytical tool for the political economies of psychiatry of regions, nations, states, and globally with the goal of helping establish the counter-apparatus. 


\section{Bibliography}

Adame, Alexandra L. 2014. "“There Needs to Be a Place in Society for Madness': The Psychiatric Survivor Movement and New Directions in Mental Health Care." Journal of Humanistic Psychology 54 (4): 456-75. https://doi.org/10.1177/0022167813510207.

Agamben, Giorgio. 2009. "What Is an Apparatus?” And Other Essays. Translated by David Kishik and Stefan Pedatella. Meridian, Crossing Aesthetics. Stanford, Calif: Stanford University Press.

Allsopp, Kate, John Read, Rhiannon Corcoran, and Peter Kinderman. 2019. "Heterogeneity in Psychiatric Diagnostic Classification." Psychiatry Research 279 (September): 15-22. https://doi.org/10.1016/j.psychres.2019.07.005.

American Association of Chairs of Departments of Psychiatry. 2020. "Home." 2020. https://www.aacdp.org/.

American Psychiatric Association. 2019a. "What Is Mental Illness?" American Psychiatric Association. 2019. https:/www.psychiatry.org/patients-families/whatis-mental-illness. . 2019b. "What Is Psychiatry?” American Psychiatric Association. 2019. https://www.psychiatry.org/patients-families/what-is-psychiatry. . 2020. "District Branches \& State Associations." Psychiatry.Org. 2020. https://www.psychiatry.org/about-apa/meet-our-organization/district-branches.

Arnold, Benjamin D., Julian Moeller, Lisa Hochstrasser, Andres R. Schneeberger, Stefan Borgwardt, Undine E. Lang, and Christian G. Huber. 2019. "Compulsory Admission to Psychiatric Wards-Who Is Admitted, and Who Appeals Against Admission?" Frontiers in Psychiatry 10 (August): 544. https://doi.org/10.3389/fpsyt.2019.00544.

Bacchi, Carol. 2012. "Why Study Problematizations? Making Politics Visible." Open Journal of Political Science 02 (01): 1-8. https://doi.org/10.4236/ojps.2012.21001.

Bell Let's Talk. 2020a. "Get Help." 2020. https://letstalk.bell.ca/en/get-help.

—. 2020b. "Our Initiatives.” 2020. https://letstalk.bell.ca/en/our-initiatives/.

Bentall, Richard. 2013. "Too Much Coercion in Mental Health Services." The Guardian. February 1, 2013.

https://www.theguardian.com/commentisfree/2013/feb/01/mental-health-servicescoercion.

Berge, Torkil, Kjersti Sunniva Bjøntegård, Petter Ekern, Martin Furan, Nils Inge Landrø, Grete J. Sølvberg Larsen, Kåre Osnes, Inger Selvaag, and Anne Helene Vedlog. 2018. "Coercive mental health care - dilemmas in the decision-making process." Tidsskrift for Den norske legeforening. https://doi.org/10.4045/tidsskr.17.0338.

Bortolotti, L., and H. Widdows. 2011. "The Right Not to Know: The Case of Psychiatric Disorders." Journal of Medical Ethics 37 (11): 673-76. https://doi.org/10.1136/jme.2010.041111.

Bredt, Christopher D., and Ewa Krajewska. 2011. "R v. Conway: UnChartered Territory for Administrative Tribunals." The Supreme Court Law Review: Osgoode's Annual Constitutional Cases Conference 54. 
Breggin, Peter R. 1975. "Psychiatry and Psychotherapy as Political Processes." American Journal of Psychotherapy 29 (3): 369-82. https://doi.org/10.1176/appi.psychotherapy.1975.29.3.369.

Burstow, Bonnie. 2015. Psychiatry and the Business of Madness: An Ethical and Epistemological Accounting. New York, NY: Palgrave Macmillan.

Campbell, Denis. 2013. "Mental Health Patients Are Being 'Detained in All but Name." The Guardian, January 30, 2013, sec. Society. https://www.theguardian.com/society/2013/jan/30/care-quality-commissionmental-health-services.

Canadian Academy of Geriatric Psychiatry. 2020. "Canadian Academy of Geriatric Psychiatry - Home.” Canadian Academy of Geriatric Psychiatry. 2020. http://www.cagp.ca/.

Canadian Academy of Psychiatry and the Law. 2020. "Welcome." Canadian Academy of Psychiatry and the Law (CAPL). 2020. https://www.capl-acpd.org/.

Canadian Medical Association. 2020. "8 BUILDING BLOCKS FOR BETTER HEALTH.” Canadian Medical Association. 2020. https://www.cma.ca/ourpurpose.

Canadian Medical Protective Association. n.d. "CMPA - What We Do." Cmpa-Acpm.Ca. Accessed June 9, 2020. https://www.cmpa-acpm.ca/en/about/what-we-do.

Canadian Network for Mood and Anxiety Treatments. n.d. "Resources." CANMAT.Org. n.d. https://www.canmat.org/resources/\#health-professionals.

Canadian Psychiatric Association. n.d. "Clinical Practice Guidelines." Canadian Psychiatric Association - Association Des Psychiatres Du Canada (blog). n.d. https://www.cpa-apc.org/clinical-resources/clinical-practice-guidelines/.

Caporaso, James A., and David P. Levine. 1992. Theories of Political Economy. Cambridge ; New York: Cambridge University Press.

Centre for Addiction and Mental Health. 2020. "About CAMH." CAMH. 2020. https://www.camh.ca/en/driving-change/about-camh.

Clarke, Stephen. 2012. "Medical Malpractice Liability: Canada | Law Library of Congress." Web page. June 2012. https://www.loc.gov/law/help/medicalmalpractice-liability/canada.php.

CMHA. 2020. "COVID-19 and Mental Health." CMHA National. April 20, 2020. https://cmha.ca/news/covid-19-and-mental-health.

Cohen, Bruce M. Z. 2016. Psychiatric Hegemony: A Marxist Theory of Mental Illness. London: Palgrave Macmillan.

Cohen, Carl I. 1997. "The Political and Moral Economy of Mental Health." Psychiatric Services 48 (6).

College of Physicians and Surgeons of Ontario. 2020. "CPSO - Home." CPSO. 2020. https://www.cpso.on.ca/.

Consent and Capacity Board of Ontario. 2020. "Consent and Capacity Board - About Us." Consent and Capacity Board. 2020. http://www.ccboard.on.ca/scripts/english/aboutus/index.asp.

Corrections and Conditional Release Act, SC 1992, c 20. 1992. CanLII. https://www.canlii.org/en/ca/laws/stat/sc-1992-c-20/latest/sc-1992-c-20.html.

Cosgrove, Lisa, Shannon M. Peters, Akansha Vaswani, and Justin M. Karter. 2018. "Institutional Corruption in Psychiatry: Case Analyses and Solutions for Reform." 
Social and Personality Psychology Compass 12 (6): e12394.

https://doi.org/10.1111/spc3.12394.

Council for Evidence-based Psychiatry. 2014. "Unrecognised Facts About Modern

Psychiatric Practice." Council for Evidence-based Psychiatry.

http://cepuk.org/wp-content/uploads/2016/05/Unrecognised-Facts-about-ModernPsychiatric-Practice.pdf.

Cox, Robert W. 1981. "Social Forces, States and World Orders: Beyond International

Relations Theory." Millennium 10 (2): 126-55. https://doi.org/10.1177/03058298810100020501.

Criminal Code RSC 1985, c C-46. 1985. CanLII. https://www.canlii.org/en/ca/laws/stat/rsc-1985-c-c-46/latest/rsc-1985-c-c46.html.

Daldal, Asli. 2014. "Power and Ideology in Michel Foucault and Antonio Gramsci: A Comparative Analysis." Review of History and Political Science 2 (2): 149-67.

Davies, Susan. 2018. "Good and Just Medicine." In Spotlight on Institutional Psychiatry: Citizens Respond to a Report by Community Legal Assistance Society on Psychiatric Incarceration in British Columbia. Vancouver BC.

Department of Finance. 2011. "Canada Health Transfer." Not available. Aem. 192011. https://www.canada.ca/en/department-finance/programs/federal-transfers/canadahealth-transfer.html.

"DSM-5 FAQ." n.d. American Psychiatric Association. n.d. https://www.psychiatry.org/psychiatrists/practice/dsm/feedback-andquestions/frequently-asked-questions.

Fine, Sean. 2017. "Doctors Tortured Patients at Ontario Mental-Health Centre, Judge Rules." The Globe and Mail, 72017.

https://www.theglobeandmail.com/news/national/doctors-at-ontario-mentalhealth-facility-tortured-patients-court-finds/article35246519/.

Foucault, Michel. 1978. The History of Sexuality. 1st American ed. New York: Pantheon Books.

1988. Madness and Civilization: A History of Insanity in the Age of Reason.

New York: Vintage Books. http://www.myilibrary.com?id=439834. 1995. Discipline and Punish: The Birth of the Prison. 2nd Vintage Books ed. New York: Vintage Books.

Foucault, Michel, Graham Burchell, Colin Gordon, and Peter Miller, eds. 1991. The Foucault Effect: Studies in Governmentality: With Two Lectures by and an Interview with Michel Foucault. Chicago: University of Chicago Press.

Foucault, Michel, and Colin Gordon. 1980. Power/Knowledge: Selected Interviews and Other Writings, 1972-1977. 1st American ed. New York: Pantheon Books.

Foucault, Michel, and Jacques Lagrange. 2006. Psychiatric Power: Lectures at the College de France, 1973-74. Basingstoke, Hampshire [England] ; New York: Palgrave Macmillan.

Frost, Tom. 2019. "The Dispositif between Foucault and Agamben." Law, Culture and the Humanities 15 (1): 151-71. https://doi.org/10.1177/1743872115571697.

Gingrich, Paul. 1999. "Sociology 250 - Notes on Max Weber." University of Regina. October 7, 1999. http://uregina.ca/ gingrich/o12f99.htm. 
Gooding, Piers, Bernadette McSherry, Cath Roper, and Flick Grey. 2018. Alternatives to Coercion in Mental Health Settings: A Literature Review Commissioned by the United Nations Office at Geneva to Inform the Report of the United Nations Special Rapporteur on the Rights of Persons with Disabilities. Melbourne: Melbourne Social Equity Institute.

Gordon, Colin. 1991. "Govemmental Rationality: An Introduction." In The Foucault Effect: Studies in Governmentality: With Two Lectures by and an Interview with Michel Foucault, edited by Michel Foucault, Graham Burchell, and Peter Miller, 1-52. Chicago: University of Chicago Press.

Gøtzsche, Peter C. 2015. Deadly Psychiatry and Organised Denial. 1. edition. København: People'sPress.

Gøtzsche, Peter C., Richard Smith, and Drummond Rennie. 2013. Deadly Medicines and Organised Crime: How Big Pharma Has Corrupted Healthcare. London: Radcliffe Publishing.

Government of Ontario. 2020a. "What OHIP Covers.” January 8, 2020. https://www.ontario.ca/page/what-ohip-covers\#section-9. . 2020b. "Roadmap to Wellness: A Plan to Build Ontario's Mental Health and Addictions System.” Ontario.Ca. February 25, 2020. https://www.ontario.ca/page/roadmap-wellness-plan-build-ontarios-mentalhealth-and-addictions-system. . 2020c. "COVID-19: Support for People: Addictions and Mental Health Services.” June 1, 2020. https://www.ontario.ca/page/covid-19-supportpeople\#mental-health-addictions-programs.

Greenberg, Gary. 2010. "Inside the Battle to Define Mental Illness | WIRED." Wired. December 27, 2010. https://www.wired.com/2010/12/ff_dsmv/. . 2013. "The Psychiatric Drug Crisis," September 3, 2013. https://www.newyorker.com/tech/annals-of-technology/the-psychiatric-drugcrisis.

Gutting, Gary, and Johanna Oksala. 2019. "Michel Foucault.” In The Stanford Encyclopedia of Philosophy, edited by Edward N. Zalta, Spring 2019. Metaphysics Research Lab, Stanford University. https://plato.stanford.edu/archives/spr2019/entries/foucault/.

Harvey, David. 2005. A Brief History of Neoliberalism. Oxford ; New York: Oxford University Press.

Health Canada. 2010. "Decision Making Framework.” Transparency - other;research. 21 2010. https://www.canada.ca/en/health-canada/services/science-research/scienceadvice-decision-making/decision-making-framework-science-research.html.

Hickey, Philip. 2014. "DSM-5: Dimensionality: Conflicts of Interest.” 2014. http://behaviorismandmentalhealth.com/2014/01/25/dsm-5-dimensionalityconflicts-of-interest/.

Insel, Thomas. 2013. "Post by Former NIMH Director Thomas Insel: Transforming Diagnosis." National Institute of Mental Health. April 29, 2013. https://www.nimh.nih.gov/about/directors/thomas-insel/blog/2013/transformingdiagnosis.shtml.

International Bipolar Foundation. 2013. "About Bipolar Disorder." International Bipolar Foundation (blog). December 7, 2013. https://ibpf.org/about-bipolar-disorder/. 
International Society for Bipolar Disorders. n.d. "ISBD - Who We Are.” ISBD. Accessed June 9, 2020. http://www.isbd.org/whoweare.

Johnston, Laura. 2017. “Operating in Darkness: BC's Mental Health Act Detention System.” Vancouver BC: Community Legal Assistance Society.

Laing, R. D. 1991. The Divided Self. Viking.

Lebenbaum, Michael, Maria Chiu, Simone Vigod, and Paul Kurdyak. 2018. "Prevalence and Predictors of Involuntary Psychiatric Hospital Admissions in Ontario, Canada: A Population-Based Linked Administrative Database Study." BJPsych Open 4 (2): 31-38. https://doi.org/10.1192/bjo.2017.4.

Leblanc, Stephanie, and Elizabeth Ann Kinsella. 2016. "Toward Epistemic Justice: A Critically Reflexive Examination of 'Sanism' and Implications for Knowledge Generation.” Studies in Social Justice 10 (1): 59-78.

Legislature of Ontario. 1990a. Education Act, R.S.O. 1990, c. E.2. https://www.ontario.ca/laws/view. . 1990b. Mental Health Act, R.S.O. 1990, c. M.7. https://www.ontario.ca/laws/view. .1990c. Provincial Offences Act, R.S.O. 1990, c. P.33. https://www.ontario.ca/laws/view. 1992. Substitute Decisions Act, 1992, S.O. 1992, c. 30. https://www.ontario.ca/laws/view. 1993. Social Contract Act, S.O. 1993, c. 5. https://www.ontario.ca/laws/view. 1996. Health Care Consent Act, SO 1996, c 2, Sch A. CanLII. https://www.canlii.org/en/on/laws/stat/so-1996-c-2-sch-a/latest/so-1996-c-2-scha.html\#document. 1997. Workplace Safety and Insurance Act, 1997, S.O. 1997, c. 16, Sched. A. https://www.ontario.ca/laws/statute/97w16. 2017. Child, Youth and Family Services Act, 2017, S.O. 2017, c. 14, Sched. 1. https://www.ontario.ca/laws/view.

Marsden, Richard. 2014. "The Nature of Capital: Marx after Foucault." London [etc.: Routledge.

Mayo Clinic. 2019. "Mental Illness - Diagnosis and Treatment - Mayo Clinic.” June 8, 2019. https://www.mayoclinic.org/diseases-conditions/mental-illness/diagnosistreatment/drc-20374974.

Mental Health Commission of Canada. 2014. "Overview on Mental Health Data in Canada." Calgary AB.

- 2016. "Making the Case for Investing in Mental Health in Canada." Economic. Mental Health Commission of Canada.

Mental Health “Recovery” Group. 2009. "Mental Health 'Recovery': Users and Refusers." Toronto: Wellesley Institute.

Ministry of Health and Long-Term Care. 2020. "Mental Health Supports From Your Home." Advertisement. Facebook. www.facebook.com.

Ministry of Health and Long-Term Care, Government of Ontario. 2017. "Health Services in Your Community - MOHLTC." Government of Ontario, Ministry of Health and Long-Term Care. July 12, 2017.

http://health.gov.on.ca/en/common/system/services/default.aspx. 
. 2019a. "Designated Psychiatric Facilities under the Mental Health Act Psychiatric Hospitals - Health Services in Your Community - MOHLTC." Government of Ontario, Ministry of Health and Long-Term Care. May 10, 2019. http:/health.gov.on.ca/en/common/system/services/psych/designated.aspx. . 2019b. "Designated Hospitals under Part XX.1 / Mental Disorder of the Criminal Code (Canada) - Psychiatric Hospitals - Health Services in Your Community - MOHLTC." Government of Ontario, Ministry of Health and LongTerm Care. June 19, 2019.

http://health.gov.on.ca/en/common/system/services/psych/designated_cc.aspx. Moncrieff, Joanna. 2008. The Myth of the Chemical Cure: A Critique of Psychiatric Drug Treatment. Basingstoke; New York: Palgrave Macmillan.

Moss, Jay H., and Donald A. Redelmeier. 2010. "Outcomes Following Appeal and Reversal of Civil Commitment." General Hospital Psychiatry 32 (1): 94-98. https://doi.org/10.1016/j.genhosppsych.2009.10.004.

“Ontario Medical Schools (OMSAS)." n.d. Ontario Universities' Application Centre. Accessed June 5, 2020. http://www.ouac.on.ca/omsas/.

Ontario Psychiatric Association. 2019. “OPA Psychotherapy Initiative.” Ontario Psychiatric Association. 2019. https://www.eopa.ca/about-us/opa-psychotherapyinitiative.

Paquin, Stéphane. 2016. Theories of International Political Economy: An Introduction. Don Mills, Ontario, Canada: Oxford University Press.

Parliament of Canada. 1985a. Canada Health Act, RSC 1985, c C-6. CanLII. https://www.canlii.org/en/ca/laws/stat/rsc-1985-c-c-6/latest/rsc-1985-c-c-6.html. . 1985b. Firearms Act RSC, 1985, c N-5. CanLII. https://www.canlii.org/en/ca/laws/stat/sc-1995-c-39/latest/sc-1995-c39.html? searchUrlHash=AAAAAQAMZmlyZWFybXMgYWN0AAAAAAE\&re sultIndex $=1$. . 1985c. National Defence Act, RSC 1985, c N-5. CanLII. https://www.canlii.org/en/ca/laws/stat/rsc-1985-c-n-5/latest/rsc-1985-c-n5.html? searchUrlHash=AAAAAQAUbmF0aW9uYWwgZGVmZW5zZSBhY3Q AAAAAAQ\&resultIndex $=1 \#$ document. 2002. Youth Criminal Justice Act, SC 2002, c 1. https://www.canlii.org/en/ca/laws/stat/sc-2002-c-1/latest/sc-2002-c1.html? searchUrlHash=AAAAAQAaeW91dGggY3JpbWluYWwganVzdGljZSB hY3QAAAAAAQ\&resultIndex $=1$. 2004. Sex Offender Information Registration Act, SC 2004, c 10. CanLII. https://www.canlii.org/en/ca/laws/stat/sc-2004-c-10/latest/sc-2004-c10.html? searchUrlHash=AAAAAQApc2V4IG9mZmVuZGVyIGluZm9ybWF0a W9uIHJIZ2lzdHJhdGlvbiBhY3QAAAAAAQ\& resultIndex=1\#document.

Patel, Vikram, Shekhar Saxena, Crick Lund, Graham Thornicroft, Florence Baingana, Paul Bolton, Dan Chisholm, et al. 2018. "The Lancet Commission on Global Mental Health and Sustainable Development." The Lancet 392 (10157): 1553-98. https://doi.org/10.1016/S0140-6736(18)31612-X.

Paul, Sayani, Arash Nakhost, Vicky Stergiopoulos, Flora I. Matheson, Alexander I.F. Simpson, and Timothy Guimond. 2020. "Perceptions of Key Stakeholders on Procedural Justice in the Consent And Capacity Board of Ontario's Hearings." 
International Journal of Law and Psychiatry 68 (January): 101515. https://doi.org/10.1016/j.ijlp.2019.101515.

Pelley, Lauren. 2016. "How to Get Help for Mental Illness in Ontario." The Toronto Start. December 11, 2016. https://www.thestar.com/life/2016/12/11/how-to-gethelp-for-mental-illness-in-ontario.html.

Perkel, Colin. 2019. "Group of Ontario Psychiatric Patients Claim They Were Tortured, Sue Province and Doctors." Globalnews.Ca. April 29, 2019. https://globalnews.ca/news/5216438/psychiatric-patients-tortured-suing-provincedoctors/.

Pifer, Mandy. 2019. "How Bell's 'Let's Talk' Campaign Harms People It Aims to Help.” Thestar.Com. January 30, 2019.

https://www.thestar.com/opinion/contributors/2019/01/30/how-bells-lets-talkcampaign-harms-people-it-aims-to-help.html.

Public Health Ontario. 2018. "Supporting the Policy Making Process." Workbook. Province of Ontario.

Ritchie, Hannah, and Max Roser. 2018. "Mental Health." Our World in Data. April 1, 2018. https://ourworldindata.org/mental-health.

Rubin, Lawrence. 2018. "Allen Frances on the DSM, Mental Illness and Humane Treatment." Psychotherapy.Net. 2018. https://www.psychotherapy.net/interview/allen-frances-interview.

Shimrat, Irit. 2018a. "Darkness Indeed." In Spotlight on Institutional Psychiatry: Citizens Respond to a Report by Community Legal Assistance Society on Psychiatric Incarceration in British Columbia. Vancouver BC.

— by Community Legal Assistance Society on Psychiatric Incarceration in British Columbia."

Soundy, Timothy. 2020. "President's Message." American Association of Chairs of Departments of Psychiatry. 2020. https://www.aacdp.org/Presidents-Message.

Springer, Simon. 2012. "Neoliberalism as Discourse: Between Foucauldian Political Economy and Marxian Poststructuralism.” Critical Discourse Studies 9 (2): 13347. https://doi.org/10.1080/17405904.2012.656375.

Steingard, Sandra. 2014. "Conflict of Interest, DSM-5, and the APA." Mad In America (blog). January 25, 2014. https://www.madinamerica.com/2014/01/conflictinterest-dsm-5-apa/.

Szasz, Thomas S. 1963. Law, Liberty and Psychiatry: An Inquiry into the Social Uses of Mental Health Practices. First. New York: Macmillan.

Szmukler, George. 2015. "Compulsion and 'Coercion' in Mental Health Care." World Psychiatry 14 (3): 259-61. https://doi.org/10.1002/wps.20264.

Teghtsoonian, Katherine. 2009. "Depression and Mental Health in Neoliberal Times: A Critical Analysis of Policy and Discourse." Social Science and Medicine 69: 2835.

Tobin Leblanc Haley, Elizabeth. 2017. "Transinstitutionalization: A Feminist Political Economy Analysis of Ontario's Public Mental Health Care System.” PhD diss., Toronto: York University.

Tsekouras, Phil. 2020. “"There's a Lot I Want to Say': Toronto Police Chief Reveals New Details in Death of Woman Who Fell from Balcony." CTV Toronto. May 
29, 2020. https://toronto.ctvnews.ca/there-s-a-lot-i-want-to-say-toronto-policechief-reveals-new-details-in-death-of-woman-who-fell-from-balcony-1.4960690.

United Nations, General Assembly. 2017. "Annual Report of the United Nations High Commissioner for Human Rights and Reports of the Office of the High Commissioner and the Secretary-General Promotion and Protection of All Human Rights, Civil, Political, Economic, Social and Cultural Rights, Including the Right to Development." Report of The United Nations High Commissioner of Human Rights A/HRC/34/32.

US National Library of Medicine. 2020. "Mental Disorders." Text. National Institute of Health. National Library of Medicine. May 30, 2020. https://medlineplus.gov/mentaldisorders.html.

Walliman, Isidor, Nicholas Tatsis, and George Zito. 1977. “On Max Weber's Definition of Power." The Australian and New Zealand Journal of Sociology 13 (3): 231-35.

Weber, Max. 1978. Economy and Society: An Outline of Interpretive Sociology. Edited by Guenther Roth and Claus Wittich. Berkeley: University of California Press.

Whitaker, Robert. 2010a. Anatomy of an Epidemic: Magic Bullets, Psychiatric Drugs, and the Astonishing Rise of Mental Illness in America. 1st ed. New York: Crown Publishers. 2010b. Mad in America: Bad Science, Bad Medicine, and the Enduring Mistreatment of the Mentally Ill. Rev. pbk. New York, NY: Basic Books.

Whitaker, Robert, and Lisa Cosgrove. 2015. Psychiatry Under the Influence Institutional Corruption, Social Injury, and Prescriptions for Reform. New York: Palgrave Macmillan US : Imprint: Palgrave Macmillan. http://link.springer.com/book/10.1057/9781137516022.

Wipond, Rob. 2018. "Introduction." In Spotlight on Institutional Psychiatry: Citizens Respond to a Report by Community Legal Assistance Society on Psychiatric Incarceration in British Columbia. Vancouver BC.

Wolframe, PhebeAnn. 2013. "The Madwoman in the Academy, or, Revealing the InvisibleStraightjacket: Theorizing and Teaching Saneism and SanePrivileg." Disability Studies Quarterly 33 (1): 1-24.

World Health Organization. 2013. "Mental Health Action Plan 2013-2020." WHO. . 2019. "Mental Disorders." World Health Organization. November 28, 2019. https://www.who.int/news-room/fact-sheets/detail/mental-disorders.

Yatham, Lakshmi N, Sidney H Kennedy, Sagar V Parikh, Ayal Schaffer, David J Bond, Benicio N Frey, Verinder Sharma, et al. 2018. "Canadian Network for Mood and Anxiety Treatments (CANMAT) and International Society for Bipolar Disorders (ISBD) 2018 Guidelines for the Management of Patients with Bipolar Disorder." Bipolar Disorders 20 (2): 97-170. https://doi.org/10.1111/bdi.12609. 
